\title{
Türkiye'deki Büyükşehirlerin Çevresel Performanslarının Entropi Temelli COPRAS ve ARAS Yöntemleri ile Değerlendirilmesi
}

\author{
DOI: $10.26466 /$ opus.556278
}

*

\author{
Onur Akçakaya* - Ezgi Dilan Urmak Akçakaya** \\ * Dr. Öğr. Üyesi. Ardahan Üniversitesi İktisadi ve İdari Bilimler Fakültesi, Ardahan/Türkiye \\ E-Posta: onurakcakaya@ardahan.edu.tr \\ ORCID: $0000-0002-7328-5380$ \\ **Arş. Gör. Ardahan Üniversitesi İktisadi ve İdari Bilimler Fakültesi, Ardahan/Türkiye \\ E-Posta: ezgidilanurmak@ardahan.edu.tr \\ ORCID: $\underline{0000-0003-3472-1837}$
}

$\ddot{O} z$

Hizlı kentleşme günümüz kentlerinde toplumsal, ekonomik ve kültürel sorunlarm yanında çevresel sorunlara da neden olmaktadır. Özellikle büyükşehirler çevresel ve ekolojik tehditlerden en fazla etkilenen yerleşmelerdir. Çevre kirliliği ve ekolojik bozulma gibi tehditleri firsata çevirmeyi başarabilen kentler, küresel ölçekte diğer rakiplerinin önüne geçmektedir. Sürdürülebilir bir kent yaratma sürecinde çevresel performansin ölçülmesi büyük önem arz etmektedir. Bu çalışmada, büyükşehirlerimizin çevresel performanslarının değerlendirilmesi ve bu alandaki farkındalı̆̆ın artırılması amaçlanmıştır. Değerlendirmede çok kriterli karar verme yöntemleri kullanılmıştır. Kullanılan kriterlerin belirlenmesinde literatür, uzman görüşleri ve verilerin erişilebilirliği etkili olmuştur. Değerlendirmede kullanılan kriterler, atık su arıtma tesisi sayısı, atık su arıtma tesislerinde arıtılan kişi başı atık su miktarı (Bin M3/Yıl), belediyelerde deşarj edilen kişi başı günlük atık su miktarı (Litre/Kişi-Gün), kişi başı çekilen günlük su miktarı (Litre/Kişi-Gün), kişi başı ortalama belediye atık miktarı (Kg/Kişi-Gün), içme ve kullanma suyu arıtma tesisi kapasitesi (Kişi başı Bin M3/Yıl), içme ve kullanma suyu arıtma tesisi sayısl, içme ve kullanma suyu arıtma tesislerinde arıtılan kişi başı su miktarı (Bin M3/Yıl), içme ve kullanma suyu şebekesi için çekilen kişi başı yeraltı suyu miktarı(Bin M3/Yıl), içme ve kullanma suyu şebekesi için çekilen kişi başı yüzey suyu miktarı(Bin M3/Yıl) ve partikül madde olmak üzere 11 tanedir. Entropi yöntemi ile kriterlerin ağırlıkları hesaplanmış, COPRAS ve ARAS yöntemleri ile büyükşehirlerin çevresel sıralamaları elde edilmiştir. Her iki yöntemde birbirine yakın stralamalar elde edilmiştir. İstanbul, Ankara, İzmir, Eskişehir ve Bursa en iyi performans gösteren kentler arasinda yer

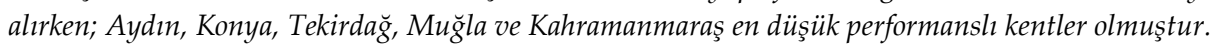

Anahtar Kelimeler: Sürdürülebilir Kentleşme, Çevresel Performans, COPRAS, ARAS, Entropi. 


\title{
Evaluation of Environmental Performances of Metropolitan Cities in Turkey with Entropy Based COPRAS and ARAS Methods
}

\begin{abstract}
Rapid urbanization causes environmental challenges as well as social, economic and cultural problems in today's cities. Especially metropolitan cities are human settlements most affected by environmental and ecological threats. Cities, turning threats such as environmental pollution and ecological deterioration into an opportunity, are ahead of their other competitors on a global scale. In the process of creating a sustainable city, measuring environmental performance has great importance. In this study, it is aimed to evaluate the environmental performance of our metropolitan cities and to raise awareness in this area. Multi-criteria decision-making methods were used in the evaluation. The literature, expert opinions and accessibility of data were effective in determining the criteria used. Eleven criteria used in the evaluation are; number of wastewater treatment plants, amount of wastewater treated in wastewater treatment plants per person (thousand M3 / year), daily wastewater discharged in municipalities (Liters/Person-Day), daily amount of water taken per person (Liters/ Person-Day), average amount of municipal waste per person ( $\mathrm{kg} /$ person-day), capacity of drinking and potable water treatment plant (thousand M3 per year), number of drinking water treatment plants, amount of drinking and potable water treated in treatment plants per person (thousand M3/ year), amount of groundwater taken for drinking and potable water network per capita (thousand M3/ year), amount of surface water taken for drinking and utility water network per capita (thousand M3/ year)) and particulate matter. The weights of the criteria were calculated by the Entropy Method, and the environmental rankings of the metropolitan cities were obtained by COPRAS and ARAS Methods. In both methods, close sequences were obtained. Istanbul, Ankara, Izmir, Eskisehir, and Bursa were among the

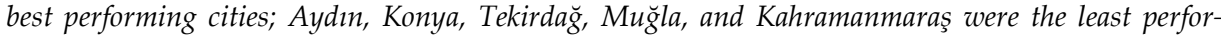
ming cities.
\end{abstract}

Keywords: Sustainable Urbanization, Environmental Performance, COPRAS, ARAS, Entropy, 


\section{Giriş}

Sanayi Devrimi'nden günümüze dünya uluslarının giriştikleri kıyasıya kalkınma yarışı, çevre kirliği ve ekolojik bozulma gibi hayati sorunlara sebebiyet vermiştir. Bu sorunlara uluslararası alanda çözüm arama sürecinde sürdürülebilirlik yaklaşımı gündeme gelmiştir. Son yıllarda sürdürülebilirlik düşüncesi küresel boyutta olduğu gibi yerelde de yükselen bir ivme yakalamıştır. Bunun en önemli nedeni, çevresel sorunların günümüzde en çok kentleri etkilemesidir. Günümüz kentleri, hemşehrileri için sürdürülebilir, doğal kaynakların ve ekolojik dengenin korunduğu yaşamsal mekânlar oluşturma konularında sorumluluk almak mecburiyetinde kalmaktadır (Akçakaya, 2016, s.48).

Dünya kentleri sürdürülebilirlik hedefleri çerçevesinde hissedilebilir bir yarış içerisine girmişlerdir. Bu rekabetin etkileri ülkemizde büyükşehirler başta olmak üzere bütün kentlerimize sorumluluk yüklemektedir. Sürdürülebilirliğin temel boyutlarından birisi olan yaşanabilir bir çevrenin yaratılmasında dünya kentlerinin seviyesine erişmek, etkin bir karar alma sürecini, kararlı uygulamaları ve rasyonel bir performans değerlendirmesini gerektirmektedir. Performans değerlendirmesinin mukayeseli bir şekilde yapılması da önemlidir. Böylelikle, kent yönetimleri çevresel sıralamadaki yerlerini, sorun yaşadıkları alanları ve en iyi uygulama sahiplerini açık bir şekilde görme fırsatı sağlayabilir.

Kapsamlı bir değerlendirmenin yapılması için birçok performans göstergesi birlikte değerlendirilmelidir. Birçok kritere göre değerlendirilmesi gereken problemlerin çözümü ise oldukça karmaşık ve zordur. Bu zorlukları aşmak adına bilim insanları tarafından bazı yöntemler geliştirilmiştir. Bu yöntemlere Çok Kriterli Karar Verme Yöntemleri (ÇKKVY) adı verilmektedir. Literatür incelendiğinde, birçok Çok Kriterli Karar Verme Yöntemi bulunduğu görülmektedir. Karar vericiler, karşılaşılan problemin yapısı ya da yöntemin problem çözmede sağladığı kolaylığa göre bu yöntemlerden uygun olanları seçebilmektedirler.

$\mathrm{Bu}$ çalışma ile büyükşehirlerin çevresel performans sıralamalarının belirlenmesi ve yerel yönetimler alanında çevresel performans değerlendirmesi ile ilgili farkındalığın artırılması amaçlanmıştır. Değerlendirmenin tek bir veri üzerinden yapılmasının mümkün olmaması nedeniyle, birçok kriter bir arada değerlendirilmiştir. Kriterlerin sayıca fazla ve 
karmaşık yapıda olması nedeniyle karar probleminin çözümünü kolaylaştırmaya yönelik olarak çok kriterli karar verme yöntemlerinden COPRAS ve ARAS yöntemleri kullanılmıştır. Çalışmada multidisipliner bir yaklaşım benimsenmiştir. Bu bağlamda, bir kamu yönetimi çalışması olan bu çalışmada çok kriterli karar verme yöntemlerinin kullanılmasının alana katkı yapması hedeflenmiştir.

Çalışmada 23 büyükşehir belediyesi değerlendirmeye tabi tutulmuş; 7 büyükşehir belediyesi ise veri eksikliği sebebiyle değerlendirmeye alınamamıştır. Değerlendirmede TÜİK veri tabanından elde edilen çevresel performans göstergeleri kullanılmıştır. Performans kriterlerinin sayısı ve çeşitleri uzman görüşleri ve veri erişilebilirliği çerçevesinde belirlenmiştir. Bu kriterler; atık su arıtma tesisi sayısı, atık su arıtma tesislerinde arıtılan kişi başı atık su miktarı (Bin M3/Yıl), belediyelerde deşarj edilen kişi başı günlük atık su miktarı (Litre/Kişi-Gün), kişi başı çekilen günlük su miktarı (Litre/Kişi-Gün), kişi başı ortalama belediye atık miktarı (Kg/Kişi-Gün), içme ve kullanma suyu arıtma tesisi kapasitesi (Kişi başı Bin M3/Yıl), içme ve kullanma suyu arıtma tesisi sayısı, içme ve kullanma suyu arıtma tesislerinde arıtılan kişi başı su miktarı (Bin M3/Yıl), içme ve kullanma suyu şebekesi için çekilen kişi başı yeraltı suyu miktar1(Bin M3/Yıl), içme ve kullanma suyu şebekesi için çekilen kişi başı yüzey suyu miktarı(Bin M3/Yıl), partikül madde olmak üzere 11 tanedir. Değerlendirme yapılırken ilk olarak Entropi yöntemi ile kriterlerin ağırlıkları hesaplanmıştır. Ardından çok kriterli karar verme yöntemlerinden COPRAS ve ARAS yöntemleri uygulanarak çevresel performans açı̧̧ından büyükşehirlerin sıralamaları elde edilmiştir. Uygulamada Excel programı kullanılmıştır.

\section{Entropi Yöntemi}

Bilgi entropisi, ilk olarak Shannon tarafından A Mathematical Theory of Communication (Shannon, 1948) makalesinde tanıtılan bir belirsizlik ölçüsüdür; mühendislik, yönetim ve benzeri birçok alanda yaygın olarak kullanılmaktadır. Bilgi entropisi fikrine göre, karar verme ortamından edinilen bilgilerin sayısı veya kalitesi karar verme probleminin doğruluğunun ve güvenilirliğinin belirleyicilerinden biridir. Bu nedenle, entropi, farklı karar verme sürecinde değerlendirme durumlarına uygulandığın- 
da çok iyi bir ölçektir ve benzer şekilde, verilerin kendisi tarafından sağlanan yararlı bilgilerin miktarını ölçmek için de entropi kullanılabilir (Wu vd., 2011, s.5163).

Çok kriterli karar verme yöntemleri ile değerlendirme yapabilmek için değerlendirmede kullanılan kriterlerin ağırlıklarına ihtiyaç duyulmaktadır. Kriter ağırlıklarının belirlenmesinde birçok yöntem vardır ancak Entropi yöntemi objektif ağırlıkları bulmak için geliştirilmiştir.

Entropi yönteminin adımları aşağıda verilmiştir (Wang ve Lee, 2009, s.8982).

Adım 1: Karar Matrisinin Eşitlik (1) İle Normalize Edilmesi

$p_{i j}=\frac{x_{i j}}{\sqrt{\sum_{i=1}^{m} x_{i j}^{i}}}$

i: Alternatifler

j: Kriterler

$p_{i j}$ : Normalize edilmiş değerler

$x_{i j}$ : i. alternatifin $\mathrm{j}$. kriter için verilen fayda değeri

Adım 2: Her Bir Kriter İ̧̧in Entropi Değeri Eşitlik (2) Yardımı İle HesaplanmaSl

$$
e_{j}=-k \sum_{i=1}^{m} p_{i j} l n p_{i j}
$$

$\mathrm{k}:(\ln (\mathrm{m}))^{-1}$

k: Entropi katsayısı

$e_{j: \text { Entropi değeri }}$

$p_{i j}$ : Normalize edilmiş değerler

Adım 3: Çeşitliliğin Derecesi Olarak Eşitlik (3) Yardımı İle $d_{j}$ Belirsizliğinin Hesaplanmast

$$
d_{j}=1-e_{j}
$$

Adım 4: Her Bir Kriterin Ağırlık Değeri Eşitlik (4) Yardımı İle Hesaplanması

$$
\begin{aligned}
& w_{j}=\frac{d_{j}}{\Sigma_{1}^{n} d j} \\
& w_{j}: \text { Ağırlık değerleri }
\end{aligned}
$$




\section{COPRAS Yöntemi}

COPRAS (Complex Proportional Assessment) Yöntemi Zavadskas ve Kaklauskas tarafından geliştirilip 1996 yılında ortaya atılmıştır. Yöntem alternatiflerin, farklı kriterler ve bunlara karşılık gelen kriter ağırlıkları bakımından performanslarını dikkate almaktadır. Bu yöntem ile hem ideal hem de en kötü çözümler göz önünde bulundurularak en iyi karar belirlenmektedir. İnşaat, mülk yönetimi, ekonomi vb. gibi çeşitli problemleri çözmek için başarıyla uygulanmıştır (Chatterjee vd., 2011, s.852).

COPRAS Yönteminin adımları aşağıda verilmiştir (Zavadskas vd.,2009, s.308-311).

\section{Adım 1: Karar Matrisinin Oluşturulması}

$x_{i j}$ değerlerinden oluşan D ile simgelenen karar matrisi oluşturulur. Karar matrisi eşitlik (5)'de gösterilmiştir.

$$
D=\left[\begin{array}{cccc}
x_{11} & x_{12} & \cdots & x_{1 n} \\
x_{21} & x_{22} & \cdots & x_{2 n} \\
\vdots & \vdots & \cdots & \vdots \\
x_{m 1} & x_{m 2} & \cdots & x_{m n}
\end{array}\right]
$$

$x_{i j}$ : j. değerlendirme ölçütü açısından i. alternatifin değeri

Adım 2: Normalize Edilmiş Karar Matrisinin Eşitlik (6) Yardımı İle Oluşturulması

$$
x_{i j}^{*}=\frac{x_{i j}}{\sum_{i=1}^{m} x_{i j}} \quad \forall j=1,2_{2} n
$$

Adım 3: Ağırlıklandırılmış Karar Matrisinin Eşittik (7) İle Oluşturulması

Ağırlıklandırılmış karar matrisi; normalize edilmiş karar matrisi sütunlarının kriterlere verilen ${ }^{w_{j}}$ ağırlık değerlerinin çarpılması ile elde edilir.

$$
\begin{aligned}
& D^{y}=d_{i j}=x_{i j}^{*}, w_{j} \\
& w_{j}: \text { j. değerlendirme ölçütünün önem düzeyi } \quad \mathrm{j}=1,2, \ldots, \mathrm{n}
\end{aligned}
$$


Adım 4: Faydalı ve Faydasız Ölçütlerin Strasıyla Eşitlik (8) ve Eşitlik (9) İle Hesaplanması

Faydalı ölçütler amaca ulaşmada daha yüksek değerlerin daha iyi durumu belirttiği ölçütleri ifade etmektedir. Faydasız ölçütler ise amaca ulaşmada daha düşük değerlerin daha iyi durumu gösterdiği ölçütleri ifade etmektedir.

$S_{i}^{+} \rightarrow$ Faydalı ölçütler için ağırlıklı normalize edilmiş karar matrisindeki değerlerin toplamıdır.

$S_{i}^{-} \rightarrow$ Faydasız ölçütler için ağırlıklı normalize edilmiş karar matrisindeki değerlerin toplamıdır.

Faydalı ölçütlerin hesaplanışı eşitlik (8), faydasız ölçütlerin hesaplanışı ise eşitlik (9) ile gösterilmektedir.

$$
\begin{array}{lll}
S_{i}^{+}=\sum_{j=1}^{k} d_{i j} & \mathrm{j}=1,2, \ldots, \mathrm{k} & \text { faydalı ölçütler } \\
S_{i}^{-}=\sum_{j=k+1}^{n} d_{i j} & \mathrm{j}=\mathrm{k}+1, \mathrm{k}+2, \ldots, \mathrm{n} & \text { faydasız ölçütler }
\end{array}
$$

Adım 5: $Q_{i}$ Göreceli Önem Değerlerinin Eşitlik (10) Yardımı İle Hesaplanması

Her alternatif için $Q_{\tilde{i}}$ göreceli önem değeri hesaplanır.

$$
Q_{i}=S_{i}^{+}+\frac{\sum_{i=1}^{m} s_{i}^{-}}{s_{i}^{-} \cdot \sum_{i=1}^{m} \frac{1}{S_{\bar{i}}}}
$$

Adım 6: En Yüksek Göreceli Önem Değerinin Eşitlik (11) Yardımı İle Hesaplanması

En yüksek göreceli önem değeri eşitlik (11) ile hesaplanır.

$$
\left.Q_{\max }=\text { en büyü } k Q_{i}\right\} \forall_{i}=1,2, \ldots m
$$

Adım 7: Alternatifler için Performans İndeksi $P_{\bar{i}}$ Değgerlerinin Eşitlik (12) Yardimiyla Hesaplanması

$P_{\bar{i}}$ performans indeksi alternatiflerin tam sıralamasını elde etmek için kullanılmaktadır.

$$
P_{i}=\frac{Q_{i}}{Q_{\max }} \cdot 100 \%
$$


Performans indeks değerleri büyükten küçüğe doğru sıralanır. $P_{i}$ performans değer indeksi 100 olan alternatif en iyi alternatif olarak belirlenmektedir.

\section{ARAS Yöntemi}

ARAS (Additive Ratio Assessment) yöntemi Zavadskas ve Turskis tarafından 2010 yılında ortaya atılmıştır. ARAS yöntemi karmaşık problemlerin basit göreceli karşılaştırmaların kullanılması ile çözülebileceği düşüncesine dayanmaktadır. Yöntem, normalize edilmiş ve ağırlıklandırılmış kriter değerlerinin toplamı ile her bir alternatifi değerlendirmeye çalışmaktadır. Bu kriterler, karşılaştırmalı alternatif tarafından elde edilen optimallik derecesini ve optimum alternatifi tanımlamaktadır (Kutut vd., 2014, s.292). ARAS yönteminin adımları aşağıda verilmiştir (Zavadskas ve Turskis, 2010, s.163-165)

Adım 1: Karar Matrisinin Oluşturulması.

ARAS yönteminde başlangıç karar matrisinde her bir kritere ait optimal değerlerden oluşan bir satır karar verici tarafından eklenmektedir.

$$
X=\left[\begin{array}{cccc}
x_{01} & x_{02} & \cdots & x_{0 n} \\
x_{11} & x_{12} & \cdots & x_{1 n} \\
\vdots & \vdots & \cdots & \vdots \\
x_{m 1} & x_{m 2} & \cdots & x_{m n}
\end{array}\right] \quad \begin{aligned}
& \mathrm{i}=0,1,2,3 \ldots, \mathrm{m} \\
& \mathrm{j}=1,2,3, \ldots, \mathrm{n}
\end{aligned}
$$

$$
\begin{array}{ll}
x_{o j}={ }_{i}^{\max x_{i j}} & \text { fayda (maksimizasyon) durumu } \\
x_{o j}={ }_{i}^{\min x_{i j}}, & \text { maliyet (minimizasyon) durumu }
\end{array}
$$

Adım 2: Karar Matrisinin Eşitlik (13) ve Eşitlik (14) Yardımı İle Normalize Edilmesi

Kriter maksimizasyon yönlü ise

$$
\bar{x}_{i j}=\frac{x_{i j}}{\sum_{i=0}^{m} x_{i j}}
$$

Kriter minimizasyon yönlü ise 2 aşamada $\quad x_{i j}=\frac{1}{x_{i j}} ; \quad \bar{x}_{i j}=\frac{x_{i j}}{\sum_{i=0}^{m} x_{i j}}$ 
Adım 3: Ă̆ırlıklandırılmış Matrisin Eşitlik (15) Yardımı İle Oluşturulması

$$
\hat{x}_{i j}=\bar{x}_{i j} w_{j} \quad \mathrm{i}=0, \ldots, \mathrm{m} ; \mathrm{j}=1, \ldots, \mathrm{n}
$$

Adım 4: Optimallik Fonksiyon Değerlerinin Eşitlik (16) Yardımı İle Hesaplanmast

$$
S_{i}=\sum_{j=1}^{n} \hat{x}_{i j} ; \quad \mathrm{i}=0, \ldots, \mathrm{m} ; \mathrm{j}=1, \ldots, \mathrm{n}
$$

Burada $S_{i}$, i. alternatifin optimal fonksiyon değeridir. En büyük $S_{i}$ değeri en iyisi iken en küçük $S_{i}$ değeri en kötüsü olarak değerlendirilmektedir.

Adım 5: Her Bir Alternatife Ait Fayda Derecesinin $\left(K_{i}\right)$ Eşitlik (17) Yardımı İle Hesaplanmast

$$
K_{i}=\frac{s_{i}}{s_{0}} ; \quad \mathrm{i}=0, \ldots, \mathrm{m}
$$

$K_{\tilde{i}}$ fayda dereceleri, alternatiflere ait $S_{\tilde{i}}$ değerlerinin $S_{o}$ optimal fonksiyon değerine oranlanması ile hesaplanmaktadır.

\section{Literatür İncelemesi}

Çok kriterli karar verme yöntemlerinin literatürde birçok karar probleminin çözümünde kullanıldığ1 görülmektedir. Ulutaş (2018, s.187-194) çalışmasında esnek üretim sistemi seçiminde kullandığ1 kriterlerin ağırlıklarının belirlenmesinde Entropi yöntemini kullanmıştır. Alternatiflerin değerlendirilmesinde ise ROV yöntemini kullanmıştır. Türkçe literatürde ROV yönteminin kullanılmadığını belirleyen Ulutaş ROV yöntemini Türkçe literatüre tanıtmayı amaçlamıştır. Çalışmada 8 alternatif işçilik maliyetinde düşüş (IMD), süreç adımları arasında biriken iş miktarındaki azalma yüzdesi (SAİMAY), kurulum maliyetindeki azalma yüzdesi (KMAY), piyasa tepkisindeki artış (PTA), kalitedeki artış (KA), sermaye ve bakım maliyeti (SBM) (bin dolar), kullanılan taban alanı (KTA) (metrekare) olmak üzere 7 kriter açısından değerlendirilmiştir. Entropi yöntemi sonucunda piyasa tepkisindeki artış (PTA) kriteri en yüksek öneme sahip kriter olarak belirlenmiştir. 
Kenger ve Organ (2017, s.152-170) çalışmalarında Çok Kriterli Karar Verme (ÇKKV) yöntemleri ile bankaya alınacak en uygun personelin seçimini amaçlanmışlardır. Bankaya alınacak personelin niteliklerinin önem dereceleri Entropi yöntemi ile belirlenmiştir. En uygun personelin seçimi ise ARAS yöntemi ile yapılmıştır. Çalışmada 5 alternatif eğitim durumu, yabancı dil bilgisi, bilgisayar tecrübesi, deneyim, referans, müşteri odaklı çalışmak, güvenilir olmak, yaratıcı-yenilikçi, çalışma arkadaşları ile uyum içerisinde olmak, fiziksel özellikler olmak üzere 10 kriter açısından değerlendirilmiştir. entropi yöntemi sonucunda güvenilir olmak kriteri en yüksek önem derecesine sahip kriter olarak belirlenmiştir. ARAS yöntemin sonucunda ise banka için en uygun aday " $\mathrm{D}$ " olarak belirlenmiştir.

Sarı (2017, s.159-170) çalışmasında 15 Ar-Ge projesinin öncelik sıralamasını amaçlamıştır. Projelerin öncelik sıralamasının belirlenmesinde proje süresi, personel sayısı, planlanan bütçe, projenin yenilikçi yönü, iyileştirme, toplam bedeli olmak üzere 6 kriter kullanılmıştır. Kriterlerin ağırlıkları Entropi yöntemi ile belirlenmiştir. TOPSIS yöntemi ile de projelerin sıralamaları gerçekleştirilmiştir. Yöntemin uygulanması sonucunda özgün tasarıma sahip plastik kilitleme makinesi tasarım ve imalatı projesi ilk sırada yer almıştır.

Bağcı ve Caba (2018, s.64-83) çalışmalarında MKYO'ların 2010-2017 yılları arasındaki nakit düzeylerini karşılaştırmayı amaçlamışlardır. Borsa İstanbul'da faaliyet gösteren BİST MKYO Endeksi'ne kayıtlı 9 firmanın nakit durumları incelenmiştir. Firmaların nakit düzeyleri Entropi ve Copras yöntemleri ile saptanmıştır. Öncelikle oranların ağırlıklarını hesaplamak için Entropi yöntemi kullanılmıştır. Değerlendirmede kullanılan kriterler cari oran, nakit oran, likidite oranı, dönen varlık devir hızı, finansal kaldıraç oranı ve borçlanma katsayısı oranıdır. Bu tespitin ardından MKYO'ların nakit seviyeleri Copras yöntemiyle hesaplanmıştır. Nakit düzeyi en iyi olan şirket İş Yatırım Ortaklığı A.Ş. iken, nakit sıkıntısı çeken şirket ise Vakıf MKYO A.Ş. olarak belirlenmiştir.

Ömürbek ve Eren (2016, s.174-187) çalışmalarında gıda sektöründe önemli bir yer tutan bir firmanın 13 finansal oran çerçevesinde 2005-2014 yılları arasındaki performansı PROMETHEE, MOORA ve COPRAS yöntemleri ile değerlendirilmiştir. Değerlendirmede kullanılan kriterler cari oran, nakit oran, asit test oranı, stoklar/toplam aktif, öz kaynak/toplam 
aktif, borçlanma oranı, finansal kaldıraç oranı, öz kaynak karlılığı, net kar marjı, fiyat kazanç oranı, net çalışma sermayesi devir hızı, stok devir hızı ve alacak devir hızı olarak belirlenmiştir. Çalışmanın sonucunda en iyi performans yılının 2014 olduğu görülmüştür.

Ömürbek ve Urmak Akçakaya (2018, s.257-278) çalışmalarında Forbes 2000 listesinde yeralan havacılık sektöründeki şirketlerin Entropi, MAUT, COPRAS Ve SAW yöntemleri ile analizini amaçlamışlardır. 21 havayolu şirketinin değerlendirmesinde satış, aktif varlıklar, pazar değeri ve çalışan sayısı olmak üzere 4 kriter kullanılmıştır. 3 yöntemin uygulanması sonucunda elde edilen 3 sıralamadan tek bir bütünleşik sıralama elde etmek amacıyla ise BORDA SAYIM yöntemi kullanılmıştır. Değerlendirme sonucunda elde edilen bütünleşik sıralamada ilk iki şirket Delta Air Lines ve United Continental Holdings şirketleri olarak belirlenmiştir.

Çakır ve Kutlu Karabıyık (2017, s.417-434) çalışmalarında bütünleşik SWARA-COPRAS yöntemi kullanarak bulut depolama hizmet sağlayıcılarının değerlendirilmesini amaçlamışlardır. Değerlendirmede aylık ücret, dosya paylaşım kolaylığı, elastikiyet, güvenlik, işletim sistemleri ile olan uyum, mobil uygulama kullanım kolaylığı, müşteri hizmetleri, senkronizasyon hızı, ücretsiz depolama alanı, üçüncü parti uygulamalar ile entegrasyon, web üzerinde kullanım kolaylığı kriterleri kullanılmıştır. En iyi bulut depolama hizmet sağlayıcısının Google Drive olduğu belirlenmişken; diğer bulut depolama hizmet sağlayıcılarından Yandex.Disk ikinci, iCloud Drive üçüncü, Dropbox dördüncü, Box beşinci ve OneDrive altıncı sırada yer almıştır.

Bircan, Arslan ve Eroğlu (2018) çalışmalarında biyogaz tesislerinin 11 kriter açısından optimallik sıralamalarını amaçlamışlardır. 11 alternatif tesisin optimal uygunluk sıralamasında MOORA ve COPRAS yöntemi kullanılmıştır. Değerlendirme toplam mesafe ortalamaları, büyükbaş hayvan sayısı, yatırım maliyeti, büyükbaş işletme sayısı, belirlenen koordinatların en yakın yerleşim yerine olan uzaklığı, en yakın belediye uzaklığı, tesiste üretilebilecek elektrik miktarı olmak üzere 7 kriter aç1sından yapılmıştır. Elde edilen sonuçlara göre 5. ve 7. Tesis yatırıma uygunlukta ilk iki sırada yer almıştır.

Podvezko (2011, s.134-146), çalışmasında çok kriterli karar verme teknikleri olan SAW ve COPRAS'ın temel özelliklerini belirtmiştir. Aynı 
zamanda tekniklerin ortak ve çeşitlilik gösteren özelliklerine de değinilmiştir. COPRAS tekniğinin özellikleri tanımlanmıştır.

Mulliner, Smallbone, ve Maliene, (2013, s.270-279) çalışmalarında sürdürülebilir konut satın alınabilirliğinin 3 yerleşim alanında değerlendirmeyi amaçlamışlardır. Değerlendirmede çevresel, sosyal ve ekonomik kriterler baz alınarak COPRAS yöntemi kullanılmıştır. Çalışmanın sonucunda, çeşitli sosyal ve çevresel kriterleri göz önünde bulundurmanın, yalnızca finansal niteliklere odaklanmaya kıyasla, uygun bir alanın hesaplanmasını büyük ölçüde etkileyebileceği ortaya konulmuştur. COPRAS, değerlendirme için etkili bir yöntem olarak bulunmuş ve diğer bölgelerde veya uluslararası alanda uygulanabilirliği belirtilmiştir.

Zavadskas, Turskis ve Vilutiene (2010, s.123-141) çalışmalarında, vakıf binası için en uygun ve güvenli olması gereken temel kurulum alternatifini seçmeyi amaçlamışlardır. Seçim bir dizi kritere dayanmaktadır: kurulum masrafları, kurulum süresi, kararların karmaşıklığı, kararların avantajları ve dezavantajları, kurulu vakıf sisteminin devredilebilirliği ve bakımı, onaylanmış kararları uygulama deneyimi. Çalışmada 3 alternatif ARAS yöntemi ile değerlendirilmiştir. En uygun alternatif A2 olarak belirlenmiştir.

Sliogeriene, Turskis ve Streimikiene (2013,s.11-20) çalışmalarında Litvanya'daki enerji üretimi teknolojilerinin analizi ve seçimini amaçlamışlardır. Kriter ağırlıkları AHP yöntemi ile belirlenirken değerlendirilen 6 alternatif ise ARAS yöntemi ile değerlendirilmiştir. Makalede tartışılan araştırma sonuçları, çoklu kriter yöntemleri kullanarak enerji üretimi teknolojilerinin değerlendirilmesinin ve seçiminin, performans, ekonomik uygunluk ve ekolojik bütünlük kriterlerini teknolojik yenilikçilik, sosyal açıdan sorumlu işletme ve sürdürülebilir kalkınma kriterleri ile karşılamanın iyi bir yolu olduğunu göstermektedir.

Shariati, Yazdani-Chamzini, Salsani, ve Tamošattenè (2014, s.410-419) çalışmalarında İran'ın Yasouj kentinde bulunan Ayerma fosfat madenindeki en iyi atık boşaltma alanını değerlendirmek ve seçmek için bulanık grup ARAS'ı temel alan bir model geliştirmeyi amaçlamışlardır. Ortaya atılan GARAS yöntemi ile teknik, ekonomik, çevresel faktörler açısından 4 alternatif değerlendirmeye alınmıştır.

Kutut, Zavadskas ve Lazauskas (2014, s.287-294) çalışmalarında ARAS ve AHP yöntemlerine dayalı model kullanarak Avrupa kentlerin- 
de kültür mirası kapsamında korumaya alınacak tarihi yapıların öncelik sıralamasının belirlenmesi amaçlamışlardır. 7 alternatif Bina çevresindeki park yerleri, yapının miras bakımından değeri, Dönemlerin kalıntıları, Eski şehir bölgesinin merkeze uzaklığı, Cephe kirliliği ile modern stil, Kültürel varlıkların restorasyonu için gerekli yatırımlar, ulaşılabilirlik, engelliler için düzenleme, yapının durumu, rahat kullanım olmak üzere 10 kriter açısından değerlendirilmiştir.

Yıldırım (2015, s.285-296) çalışmasında Çok Kriterli Karar Verme yöntemleri sınıfının bir üyesi olan ARAS yöntemi incelenerek yerel literatüre yeni bir alternatif yöntem olarak önermiştir. ARAS yönteminin literatürde kullanım alanları incelendikten sonra yöntemin aşamaları detaylı olarak ele alınmış ve Konut satın probleminde ailenin satın alma alternatiflerini değerlendirdiği bir uygulama gerçekleştirilmiştir. Konut fiyatı (TL), net kullanım alanı (m2 ), işyerine uzaklık $(\mathrm{km})$, konut oda sayısı (adet), binaya ait yeşil alan ( $\mathrm{m} 2$ ) ve binanın yaşı, kriterleri üzerinden 5 alternatif ARAS yöntemi değerlendirilmiştir. yöntem sonucunda ilk s1rada a2 konutu yer almıştır.

Medineckiene, Zavadskas, Bjork ve Turskis (2015, s.11-18) çalışmalarında 6 alternatif yapının sürdürülebilirlikleri değerlendirilmişlerdir. Değerlendirmede kriter ağırlıkları AHP ile elde edilmiş olup alternatiflerin sıralanması ise ARAS yöntemi ile gerçekleştirilmiştir. Değerlendirme enerji, kapalı ortam, malzemeler ve kimyasallar olmak üzere 3 ana kriter açısından yapılmıştır.

Ercan ve Kundakçı (2017, s.83-105) çalışmalarında Çok Kriterli Karar Verme yöntemlerinden ARAS ve OCRA (Operational Competitiveness RAting) yöntemleri ile bir tekstil işletmesinde numune tasarımında kullanılacak desen programı seçimi yapılması amaçlanmıştır. Desen programı seçiminde dikkate alınan kriterlerin ağırlıkları MACBETH (Measuring Attractiveness by a Categorical Based Evaluation TecHnique) yöntemi kullanılarak bulunmuştur, desen programı alternatiflerinin değerlendirilmesinde ARAS ve OCRA yöntemlerinden yararlanılmış ve elde edilen sonuçlar karşılaştırılmıştır. Her iki yöntem ile aynı sıralama elde edilmiş, sıralama sonuçlarına göre en uygun desen programı belirlenmiş ve tekstil işletmesine bu programı satın alması önerilmiştir. 3 alternatif desen programı kullanım zorluğu, hizmet kalitesi, özellik sayısı, görsel çıktı kalitesi, marka güvenirliği, zaman kaybı ve fiyat olmak üzere 7 kri- 
ter açısından değerlendirilmiştir. ARAS ve OCRA yöntemlerinde A1 alternatifi ilk sırada yer almıştır.

Tunca, Ömürbek, Urmak Akçakaya ve Akçakaya (2018, s.1837-1847) çalışmalarında en değerli 10 küresel markanın çok kriterli karar verme yöntemleri ile değerlendirmesini amaçlamışlardır. 10 şirketin marka değeri, marka geliri, reklam harcamaları, kar, aktif varlıklar, piyasa değeri, çalışan sayısı kriterleri açısından değerlendirilmiştir. Çalışmada ilk olarak Entropi yöntemi ile 7 kriterin ağırlıkları hesaplanmıştır. Markaların sıralaması ise COPRAS ve ARAS yöntemleri ile belirlenmiştir. Yöntemlerin uygulanması sonucunda COPRAS yönteminde Facebook markası ilk sırada yer alırken ARAS yönteminde ise Apple markası ilk sırada yer almıştır.

Aytaç Adalı ve Tuş Işık (2016, s.124-138) çalışmalarında klima seçimini amaçlamışlardır. Değerlendirmede COPRAS ve ARAS yöntemlerini kullanmışlardır. Çalışmada 6 alternatif enerji verimliliği oranı, performans katsayısı, iyonlaştırıcı, maliyet, maksimum ses seviyesi (iç mekan), maksimum ses seviyesi (dış mekan), 1sıtma için watt tüketimi ve soğutma için watt tüketimi olmak üzere 8 kriter açısından değerlendirilmiştir. Her iki yöntemde de ilk sırada A1 alternatifi ilk sırada yer almıştır.

Çalışmamızın konusunu oluşturan kentsel sürdürülebilirliğin değerlendirilmesi ile ilgili yazında önem arz eden çalışmalar olduğu görülmektedir. Bu anlamda sürdürülebilir kalkınma konusunda en önemli çalışmalardan birisi B.M. Çevre ve Kalkınma Komisyonu tarafından yayımlanan "Ortak Geleceğimiz" (1987) isimli rapordur. Brundtland Raporu olarak da bilinen bu çalışma sürdürülebilirliği uluslararası alanda gündeme taşıyarak; çevresel, ekonomik ve sosyal boyutlarını ortaya koymuştur.

Brundtland Raporu'ndan sonra sürdürülebilirlik çalışmaları kent alanına da yayılmıştır. Anders (1991) çalışmasında kentlerin sürdürülebilir yerleşimlere dönüştürülmesinde gerekli olan ilkeleri ortaya koymuştur. Verbruggen ve Kuik (1991, s.1-6) çalışmasında, sürdürülebilir kalkınmanın değerlendirilmesi için gerekli olan performans göstergeleri üzerine bir çerçeve çizmiştir. Maclaren (1993) kentsel sürdürülebilirlik alanındaki çalışmasında Kanada'daki kentlerin sürdürülebilirlik seviyelerini ortaya koymuştur. Maclaren (1996, s.184-202) çalışmasında ise daha çok kentsel sürdürülebilirliğin ölçülmesi ve raporlanması ile ilgili süreci ortaya 
koymaya yönelik bir çalışma yapmıştır. Mega ve Pedersen (1998) çalışmalarında, performans değerlendirmesinde kullanılmak üzere kentsel sürdürülebilirlik göstergelerini tespit etmeye çalışmışlardır. Newman (1999, s.219-226) çalışmasında sürdürülebilirlik ve kent arasındaki ilişkiyi ortaya koymayı amaçlamıştır. Newman ve Kenworthy (1999) çalışmalarında kentlerde otomobil kullanımının kent sürdürülebilirliğine etkilerini ve doğa dostu ulaşım teknolojilerini tartışmışlardır. Brassoulis (2001) çalışmasında sürdürülebilir kalkınmanın tüm boyutlarında performans göstergelerini tespit etmeye yönelik bir çalışma yapmıştır. Akçakaya (2016, s.47-64) çalışmasında kent sürdürülebilirliğinin sağlanması ve değerlendirilmesi açılarından yerel yönetimlerin sorumluluklarını ortaya koyan bir çalışma yapmıştır. Gök ve Yiğit (2017, s.253-273) çalışmalarında Türkiye'deki metropoliten ölçekli kentleri sürdürülebilirliğin sosyal, ekonomik ve çevresel kriterleri bakımından değerlendirilmiştir. Değerlendirmede çok kriterli karar verme yöntemlerinden TOPSİS kullanılmıştır. Literatür incelemesi Tablo 1'de verilmiştir.

Tablo 1. Literatür İncelemesi

\begin{tabular}{ll}
\hline Entropi Yöntemi İle Yapılan Bazı Çalışmalar & \\
\hline Esnek Üretim Sistemi Seçimi & Ulutaş (2018, s.187-194) \\
\hline Banka Personel Seçimi & Kenger ve Organ (2017,s.152-170) \\
\hline Endüstri İşletmelerinde AR-GE Projelerinin Sıralanması & Sarı (2017,s.159-170) \\
\hline $\begin{array}{l}\text { Menkul Kıymet Yatırım Ortaklıklarının Nakit Düzeylerinin } \\
\text { Kıyaslanması }\end{array}$ & Bağcı ve Caba (2018,s.64-83) \\
\hline COPRAS Yöntemi İle Yapılan Bazı Çalışmalar & \\
\hline Oran Analizi Sonuçlarının Değerlendirilmesi & Ömürbek ve Eren (2016,s.174-187) \\
\hline $\begin{array}{l}\text { Forbes 2000 Listesinde Yer Alan Havacılık Sektöründeki } \\
\text { Şirketlerin Analizi }\end{array}$ & Ömürbek ve Urmak (2018,s.257-278) \\
\hline Bulut Depolama Hizmet Sağlayıcılarının Değerlendirilmesi & Çakır ve Kutlu (2017,s.417-434) \\
\hline Biyogaz Tesislerinin Optimallik Sıralaması & Bircan vd., (2018) \\
\hline COPRAS ve SAW Yöntemlerinin Karşılaştırılması & Podvezko (2011,s.134-146) \\
\hline Sürdürülebilir Konut Alım Gücünün Değerlendirilmesi & Mulliner vd. (2013,s.270-279) \\
\hline ARAS Yöntemi İle Yapılan Bazı Çalışmalar & \\
\hline Vakıf Binaları İçin Tesisat Seçimi & Zavadskas vd. (2010,s. 123-141) \\
\hline Enerji Üretim Alternatiflerinin Analizi & Sliogerience vd. (2013,s. 11-20) \\
\hline Atık Döküm Yeri Seçimi & Shariati vd. (2014,s. 410-419) \\
\hline $\begin{array}{l}\text { Avrupa kentlerinde kültür mirası kapsamında korumaya } \\
\text { alınacak tarihi yapıların öncelik sıralamasının belirlenmesi }\end{array}$ & Kutut vd. (2014,s.287-294) \\
\hline Konut Seçimi & Yıldırım (2015,s. 285-296) \\
\hline Yapıların Sürdürülebilirliklerinin Değerlendirilmesi & Medineckiene vd. (2015,s. 11-18) \\
\hline Tekstil İşletmesi için Desen Programı Seçimi & Ercan ve Kundakcı (2017,s. 83-105) \\
\hline En Değerli 10 Küresel Markanın Değerlendirilmesi & Tunca vd. (2018,s.1837-1847) \\
\hline Klima Seçimi & Aytaç Adalı ve Tuş (2016,s. 124-138)
\end{tabular}


Türkiye' deki Büyükşehirlerin Çevresel Performanslarının Entropi Temelli COPRAS ve ARAS Yöntemleri ile Değerlendirilmesi

Kentsel Sürdürülebilirlik ile İlgili Yapılan Çalışmalar

\begin{tabular}{|c|c|}
\hline Ortak Geleceğimiz & $\begin{array}{l}\text { BM Dünya Çevre ve kalkınma } \\
\text { Kom.(1987) }\end{array}$ \\
\hline Sürdürülebilir Kentler Hareketi & Anders (1991) \\
\hline Sürdürülebilir Kalkınma Göstergeleri & Verbruggen ve Kuik (1991,s.1-6) \\
\hline Sürdürülebilir Topluluklara Doğru & Roseland (1992) \\
\hline Sürdürülebilirliğin Evrimi & Kidd (1992:1-26) \\
\hline Kanada'da Sürdürülebilir Kentsel Kalkınma & Maclaren (1993) \\
\hline Kentler ve Sürdürülebilir Kalkınma & Mitlin ve Satterthwaite (1994) \\
\hline Planlama ve Sürdürülebilirlik & Beatley, (1995) \\
\hline Daha İyi Kentler İçin Bir Değerlendirme & Diver vd. (1996) \\
\hline Kentsel Sürdürülebilirlik Raporlaması & Maclaren, (1996,s.184-202) \\
\hline Kentsel Sürdürülebilirlik Göstergeleri & Mega ve Pedersen (1998) \\
\hline Sürdürülebilirlik ve Kentler & Newman $(1999, \mathrm{~s} .219-226)$ \\
\hline $\begin{array}{l}\text { Sürdürülebilirlik ve Kentler: Otomobil Bağımlılığının Üste- } \\
\text { sinden Gelmek }\end{array}$ & Newman ve Kenworthy (1999) \\
\hline Sürdürülebilir Kalkınma ve Göstergeleri & Briassoulis, (2001) \\
\hline Kentsel Kalkınmanın Gelişen Bir Türü & Couch vd. (2005,s. 117-136) \\
\hline Yeşil Alanlar ve Kentsel Isı Çalışması & Wong ve Yu (2005,s.547-558) \\
\hline $\begin{array}{l}\text { Sürdürülebilir İnovatif Kentlerin Boyutlarının Değerlendiril- } \\
\text { mesi }\end{array}$ & Ma, Wang ve Liu, (2014) \\
\hline $\begin{array}{l}\text { Kentsel Sürdürülebilirliğin Ölçülmesi Bağlamında Yerel } \\
\text { Yönetimlerin Fonksiyonu }\end{array}$ & Akçakaya (2016,s. 47-64) \\
\hline $\begin{array}{l}\text { Kentsel Sürdürülebilirliğin Uygulanmasında Kamu Özel } \\
\text { Sektör Ortaklığı } \\
\text { Yaklaşımı }\end{array}$ & Akçakaya (2017,s.46-62) \\
\hline $\begin{array}{l}\text { Sürdürülebilir Arazi Kullanımı Planlamasında Bir Model } \\
\text { YaklaşımıTürkiye'deki Büyükşehirlerin Sürdürülebilirlik } \\
\text { Kriterleri Açısından Değerlendirilmesi }\end{array}$ & $\begin{array}{l}\text { Akten ve Akten }(2010, \text { s. } 85-89) \\
\text { Gök ve Yiğit }(2017, \mathrm{s.253-273)}\end{array}$ \\
\hline
\end{tabular}

\section{Kentlerin Çevresel Performanslarının Çok Kriterli Karar Verme Yön- temleri İle Analizi}

Çalışmada Türkiye'de bulunan büyükşehirlerin çevresel performanslarının değerlendirmesinin yapılması amaçlanmıştır. Değerlendirme Çok Kriterli Karar Verme yöntemlerinden olan COPRAS ve ARAS yöntemleri ile gerçekleştirilmiştir. Çalışmada ilk olarak Entropi yöntemi ile kriter ağırlıkları elde edilmiştir. Elde edilen kriter ağırlıklarının yardımı ile COPRAS ve ARAS yöntemleri uygulanmış ve büyükşehirlerin çevresel performanslarına göre sıralamaları elde edilmiştir.

Türkiye'de 30 büyükşehir bulunmaktadır ancak bunlar arasından 7 büyükşehir veri eksikliği nedeniyle değerlendirmeye tabi tutulamamış- 
tır. 23 büyükşehrin çevresel performansları 11 kriter açısından değerlendirilmiştir.

Uzman görüşlerine dayanarak belirlenen 11 kriter:

- Atık su arıtma tesisi sayısı,

- Atık su arıtma tesislerinde arıtılan kişi başı atık su miktarı (Bin $\mathrm{M} 3 / \mathrm{Y}_{11)}$,

- Belediyelerde deşarj edilen kişi başı günlük atık su miktarı (Litre/Kişi-Gün),

- Kişi başı çekilen günlük su miktarı (Litre/Kişi-Gün),

- Kişi başı ortalama belediye atık miktarı (Kg/Kişi-Gün),

- İçme ve kullanma suyu arıtma tesisi kapasitesi (Kişi başı Bin $\left.\mathrm{M} 3 / \mathrm{Y}_{1}\right)$, ,s.

- İçme ve kullanma suyu arıtma tesisi sayısı,

- İçme ve kullanma suyu arıtma tesislerinde arıtılan kişi başı su miktar1 (Bin M3/Yil),

- İçme ve kullanma suyu şebekesi için çekilen kişi başı yeraltı suyu miktarı(Bin M3/Yil),

- İçme ve kullanma suyu şebekesi için çekilen kişi başı yüzey suyu miktarı(Bin M3/Yil),

- Partikül madde

Uygulama Excel programı ile gerçekleştirilmiştir. Büyükşehirlere ait veriler Türkiye İstatistik Kurumu'nun resmi internet sitesinden elde edilmiştir. Değerlendirilen 23 büyükşsehir ve kodları Tablo 2' de verilmiştir.

Tablo 2. Büyükşehirler ve Kodları

\begin{tabular}{lllllllr}
\hline Büyükşehir & Kod & Büyükşehir & Kod & Büyükşehir & Kod & Büyükşehir & Kod \\
\hline Adana & B1 & Mersin & B7 & Aydın & B13 & Ordu & B19 \\
\hline Ankara & B2 & İstanbul & B8 & Balıkesir & B14 & Sakarya & B20 \\
\hline Bursa & B3 & İzmir & B9 & Erzurum & B15 & Samsun & B21 \\
\hline Gaziantep & B4 & Şanlıurfa & B10 & Eskişehir & B16 & Tekirdağ & B22 \\
\hline Kocaeli & B5 & Hatay & B11 & K. Maraş & B17 & & \\
\hline Konya & B6 & Diyarbakır & B12 & Muğla & B18 & & \\
\hline
\end{tabular}

Değerlendirmede kullanılan 11 kriter, kodları ve kriter türleri ise Tablo 3'de gösterilmiştir. 
Tablo 3. Kriterler ve Kodlart

\begin{tabular}{|c|c|c|}
\hline Kriter & Kod & KriterTürü \\
\hline Atık su arıtma tesisi sayısı & K1 & MAX \\
\hline Atık su arıtma tesislerinde arıtılan kişi başı atık su miktarı (Bin M3/Yıl) & K2 & MAX \\
\hline Belediyelerde deşarj edilen kişi başı günlük atık su miktarı (Litre/Kişi-Gün) & K3 & MIN \\
\hline Kişi başı çekilen günlük su miktarı (Litre/Kişi-Gün) & K4 & MIN \\
\hline Kişi başı ortalama belediye atık miktarı (Kg/Kişi-Gün) & K5 & MIN \\
\hline İçme ve kullanma suyu arıtma tesisi kapasitesi (Kişi başı Bin M3/Yıl) & K6 & MAX \\
\hline İçme ve kullanma suyu arıtma tesisi sayısı & K7 & MAX \\
\hline $\begin{array}{l}\text { İçme ve kullanma suyu arıtma tesislerinde arıtılan kişi başı su miktarı (Bin } \\
\text { M3/Yıl) }\end{array}$ & K8 & MAX \\
\hline $\begin{array}{l}\text { İçme ve kullanma suyu şebekesi için çekilen kişi başı yeraltı suyu miktarı(Bin } \\
\text { M3/Yıl) }\end{array}$ & K9 & MiN \\
\hline $\begin{array}{l}\text { İçme ve kullanma suyu şebekesi için çekilen kişi başı yüzey suyu miktarı(Bin } \\
\text { M3/Yıl) }\end{array}$ & K10 & MiN \\
\hline Partikül madde & K11 & MiN \\
\hline
\end{tabular}

\section{Kriter Ağırlıklarının Entropi Yöntemi İle Belirlenmesi}

11 kritere ait göreceli önem değerleri (ağırlıkları) Entropi yöntemi ile elde edilmiştir.

\section{Adım 1: Karar Matrisinin Normalize Edilmesi}

Her bir alternatifin belirlenen kriterlere ait değerlerinden oluşan karar matrisi Tablo 4'de verilmiştir. Entropi yönteminin adımları bu matris üzerinde uygulanmıştır.

Tablo 4. Karar Matrisi

\begin{tabular}{llllllllllll}
\hline & K1 & K2 & K3 & K4 & K5 & K6 & K7 & K8 & K9 & K10 & K11 \\
\hline B1 & 7 & 0,056 & 163 & 212 & 0,89 & 0,082 & 1 & 0,066 & 0,009 & 0,066 & 58 \\
B2 & 26 & 0,056 & 162 & 227 & 1,14 & 0,129 & 71 & 0,079 & 0,004 & 0,078 & 58 \\
B3 & 109 & 0,047 & 134 & 163 & 1,11 & 0,071 & 18 & 0,039 & 0,014 & 0,045 & 81 \\
B4 & 4 & 0,058 & 187 & 338 & 0,89 & 0,086 & 4 & 0,079 & 0,006 & 0,115 & 60 \\
B5 & 21 & 0,067 & 191 & 238 & 1 & 0,096 & 14 & 0,078 & 0,007 & 0,077 & 48 \\
B6 & 19 & 0,036 & 182 & 201 & 1,06 & 0,022 & 9 & 0,010 & 0,063 & 0,009 & 56 \\
B7 & 11 & 0,046 & 174 & 238 & 1,21 & 0,079 & 1 & 0,059 & 0,026 & 0,059 & 65 \\
B8 & 82 & 0,080 & 226 & 189 & 1,3 & 0,105 & 21 & 0,065 & 0,001 & 0,067 & 53 \\
B9 & 58 & 0,070 & 195 & 173 & 1,32 & 0,102 & 43 & 0,054 & 0,038 & 0,024 & 41 \\
B10 & 2 & 0,005 & 210 & 172 & 1,01 & 0,055 & 1 & 0,042 & 0,016 & 0,042 & 45 \\
B11 & 8 & 0,022 & 193 & 183 & 0,91 & 0,030 & 4 & 0,001 & 0,063 & 0,001 & 65 \\
B12 & 1 & 0,028 & 81 & 135 & 1,06 & 0,057 & 3 & 0,044 & 0,004 & 0,043 & 65 \\
B13 & 33 & 0,066 & 245 & 233 & 1,44 & 0,019 & 31 & 0,016 & 0,068 & 0,014 & 66 \\
B14 & 18 & 0,039 & 153 & 238 & 1,54 & 0,106 & 8 & 0,038 & 0,032 & 0,054 & 47 \\
B15 & 7 & 0,034 & 121 & 309 & 0,81 & 0,092 & 3 & 0,077 & 0,043 & 0,070 & 39
\end{tabular}




\begin{tabular}{lllllllllllll} 
B16 & 1 & 0,056 & 159 & 180 & 1,04 & 0,141 & 6 & 0,050 & 0,013 & 0,051 & 24 \\
B17 & 3 & 0,006 & 197 & 309 & 0,71 & 0,029 & 1 & 0,001 & 0,077 & 0,032 & 77 \\
B18 & 29 & 0,070 & 254 & 239 & 1,97 & 0,050 & 4 & 0,033 & 0,068 & 0,017 & 81 \\
B19 & 25 & 0,048 & 166 & 284 & 0,96 & 0,077 & 24 & 0,049 & 0,028 & 0,049 & 51 \\
B20 & 3 & 0,039 & 214 & 343 & 1,13 & 0,136 & 11 & 0,077 & 0,058 & 0,066 & 67 \\
B21 & 13 & 0,044 & 158 & 220 & 1,29 & 0,086 & 20 & 0,068 & 0,011 & 0,064 & 52 \\
B22 & 14 & 0,015 & 98 & 176 & 1,37 & 0,018 & 9 & 0,005 & 0,057 & 0,006 & 66 \\
B23 & 15 & 0,069 & 325 & 379 & 0,79 & 0,117 & 15 & 0,085 & 0,0007 & 0,097 & 59 \\
\hline
\end{tabular}

Karar matrisinin normalizasyonu Eşitlik 1 yardımı ile hesaplanmış olup normalize edilmiş karar matrisi Tablo 5'de gösterilmiş̧ir.

Tablo 5. Normalize Edilmiş Karar Matrisi $\left(P_{i j}\right.$ değerleri)

\begin{tabular}{|c|c|c|c|c|c|c|c|c|c|c|c|}
\hline & K1 & K2 & K3 & K4 & K5 & K6 & K7 & K8 & K9 & K10 & K11 \\
\hline B1 & 0,0424 & 0,2325 & 0,1797 & 0,1844 & 0,1597 & 0,2002 & 0,0098 & 0,2485 & 0,0468 & 0,2406 & 0,2047 \\
\hline B2 & 0,1575 & 0,2306 & 0,1786 & 0,1974 & 0,2046 & 0,3137 & 0,6940 & 0,2972 & 0,0198 & 0,2812 & 0,2047 \\
\hline B3 & 0,6604 & 0,1953 & 0,1477 & 0,1418 & 0,1992 & 0,1718 & 0,1759 & 0,1481 & 0,0706 & 0,1646 & 0,2858 \\
\hline B4 & 0,0242 & 0,2380 & 0,2061 & 0,2940 & 0,1597 & 0,2096 & 0,0391 & 0,2974 & 0,0306 & 0,4185 & 0,2117 \\
\hline B5 & 0,1272 & 0,2778 & 0,2106 & 0,2070 & 0,1795 & 0,2325 & 0,1368 & 0,2958 & 0,0373 & 0,2804 & 0,1694 \\
\hline B6 & 0,1151 & 0,1500 & 0,2006 & 0,1748 & 0,1903 & 0,0542 & 0,0880 & 0,0386 & 0,3311 & 0,0319 & 0,1976 \\
\hline B7 & 0,0666 & 0,1897 & 0,1918 & 0,2070 & 0,2172 & 0,1930 & 0,0098 & 0,2236 & 0,1344 & 0,2148 & 0,2294 \\
\hline B8 & 0,4968 & 0,3327 & 0,2491 & 0,1644 & 0,2333 & 0,2545 & 0,2053 & 0,2467 & 0,0042 & 0,2427 & 0,1870 \\
\hline B9 & 0,3514 & 0,2911 & 0,2150 & 0,1505 & 0,2369 & 0,2469 & 0,4203 & 0,2026 & 0,2005 & 0,0875 & 0,1447 \\
\hline B10 & 0,0121 & 0,0212 & 0,2315 & 0,1496 & 0,1813 & 0,1341 & 0,0098 & 0,1576 & 0,0856 & 0,1515 & 0,1588 \\
\hline B11 & 0,0485 & 0,0904 & 0,2128 & 0,1592 & 0,1633 & 0,0732 & 0,0391 & 0,0027 & 0,3312 & 0,0021 & 0,2294 \\
\hline B12 & 0,0061 & 0,1142 & 0,0893 & 0,1174 & 0,1903 & 0,1382 & 0,0293 & 0,1668 & 0,0204 & 0,1560 & 0,2294 \\
\hline B13 & 0,1999 & 0,2743 & 0,2701 & 0,2027 & 0,2585 & 0,0471 & 0,3030 & 0,0591 & 0,3532 & 0,0510 & 0,2329 \\
\hline B14 & 0,1091 & 0,1602 & 0,1687 & 0,2070 & 0,2764 & 0,2567 & 0,0782 & 0,1446 & 0,1667 & 0,1940 & 0,1659 \\
\hline B15 & 0,0424 & 0,1411 & 0,1334 & 0,2688 & 0,1454 & 0,2245 & 0,0293 & 0,2887 & 0,2259 & 0,2525 & 0,1376 \\
\hline B16 & 0,0061 & 0,2308 & 0,1753 & 0,1566 & 0,1867 & 0,3420 & 0,0586 & 0,1899 & 0,0698 & 0,1857 & 0,0847 \\
\hline B17 & 0,0182 & 0,0266 & 0,2172 & 0,2688 & 0,1274 & 0,0708 & 0,0098 & 0,0029 & 0,4046 & 0,1150 & 0,2717 \\
\hline B18 & 0,1757 & 0,2912 & 0,2800 & 0,2079 & 0,3536 & 0,1205 & 0,0391 & 0,1235 & 0,3576 & 0,0634 & 0,2858 \\
\hline B19 & 0,1515 & 0,2006 & 0,1830 & 0,2470 & 0,1723 & 0,1881 & 0,2346 & 0,1838 & 0,1455 & 0,1769 & 0,1800 \\
\hline B20 & 0,0182 & 0,1593 & 0,2359 & 0,2983 & 0,2028 & 0,3296 & 0,1075 & 0,2914 & 0,3015 & 0,2385 & 0,2364 \\
\hline B21 & 0,0788 & 0,1834 & 0,1742 & 0,1913 & 0,2315 & 0,2103 & 0,1955 & 0,2563 & 0,0572 & 0,2329 & 0,1835 \\
\hline B22 & 0,0848 & 0,0630 & 0,1080 & 0,1531 & 0,2459 & 0,0447 & 0,0880 & 0,0204 & 0,2964 & 0,0203 & 0,2329 \\
\hline B23 & 0,0909 & 0,2873 & 0,3583 & 0,2948 & 0,1418 & 0,2835 & 0,1466 & 0,3195 & 0,0392 & 0,3502 & 0,2082 \\
\hline
\end{tabular}

Adım 2: Her Bir Kriter İçin Entropi Değerinin Hesaplanması

Her bir kritere ait Entropi değeri $\left({ }^{{ }}{ }_{j}\right)$ Eşitlik 2 yardımı ile hesaplanmış ve elde edilen değerler Tablo 6 'da verilmiştir.

Tablo 6. Entropi Değerleri $\left({ }^{e_{j}}\right)$

\begin{tabular}{|c|c|c|c|c|c|c|c|c|c|c|c|}
\hline & K1 & $\mathrm{K} 2$ & K3 & K4 & K5 & K6 & K7 & K8 & K9 & K10 & K11 \\
\hline$e_{f}$ & 1,441 & 2,150 & 2,306 & 2,321 & 2,330 & 2,136 & 1,474 & 2,011 & 1,750 & 2,006 & 2,332 \\
\hline
\end{tabular}




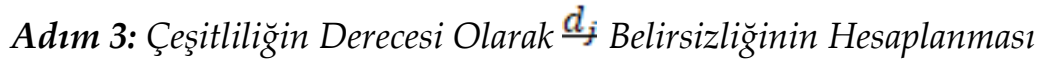

Eşitlik 3 yardımı ile her bir kritere ait $d_{j}$ değerleri hesaplanmıştır. Elde edilen değerler Tablo 7 'de verilmiştir.

Tablo 7. ${ }^{d}{ }_{j}$ Değerleri

\begin{tabular}{rrrrrrrrrrrr}
\hline & K1 & K2 & K3 & K4 & K5 & K6 & K7 & K8 & K9 & K10 & K11 \\
\hline $\boldsymbol{d}_{\boldsymbol{f}}$ & $-0,44$ & $-1,15$ & $-1,30$ & $-1,32$ & $-1,33$ & $-1,13$ & $-0,47$ & $-1,01$ & $-0,75$ & $-1,00$ & $-1,33$ \\
\hline
\end{tabular}

Adım 4: Her Bir Kriterin A ̆̆̊rlık Değgerinin Hesaplanması

Ağırlık değerleri Eşitlik 4 ile hesaplanmıştır. Elde edilen değerler Tablo 8 'de gösterilmiştir.

Tablo 8. A ğırlık Değerleri $\left({ }^{W_{j}}\right)$

\begin{tabular}{rrrrrrrrrrrr}
\hline & K1 & K2 & K3 & K4 & K5 & K6 & K7 & K8 & K9 & K10 & K11 \\
\hline $\boldsymbol{w}_{\boldsymbol{f}}$ & 0,039 & 0,102 & 0,115 & 0,117 & 0,118 & 0,100 & 0,042 & 0,089 & 0,066 & 0,089 & 0,118 \\
\hline
\end{tabular}

Kriter ağırlıkları incelendiğinde K11 kodlu partikül madde kriterinin 0,1183 değer ile en yüksek değere sahip olduğu görülmektedir ve en fazla öneme sahip kriter olarak belirlenmiştir. 0.0392 değer ile K1 kodlu atık su arıtma tesisi sayısı kriteri ise çevresel performans değerlendirmesinde en az öneme sahip kriter olarak belirlenmiştir.

COPRAS Yöntemi İle Büyükşehirlerin Çevresel Performanslarının Analizi

Entropi yöntemi ile kriterlerin ağırlıklarının bulunmasından sonra COPRAS yöntemi ile büyükşehirlerin çevresel performansları değerlendirilmiş ve sıralamaları elde edilmiştir. Değerlendirmede kullanılan alternatifler (büyükşehirler) ve kodları Tablo 2'de gösterilmiş olup değerlendirmede kullanılan kriterler ve kodlar ise Tablo 3'de gösterilmiştir.

\section{Adım 1: Karar Matrisinin Oluşturulması}

COPRAS yönteminin uygulanacağ oluşturulmuştur. Alternatiflerin ve kriterlerin bulunduğu karar matrisi Tablo 9'da gösterilmiştir. 
Tablo 9. Karar Matrisi

\begin{tabular}{llllllllllll}
\hline & K1 & K2 & K3 & K4 & K5 & K6 & K7 & K8 & K9 & K10 & K11 \\
\hline B1 & 7 & 0,056 & 163 & 212 & 0,89 & 0,082 & 1 & 0,066 & 0,009 & 0,066 & 58 \\
B2 & 26 & 0,056 & 162 & 227 & 1,14 & 0,129 & 71 & 0,079 & 0,004 & 0,078 & 58 \\
B3 & 109 & 0,047 & 134 & 163 & 1,11 & 0,071 & 18 & 0,039 & 0,014 & 0,045 & 81 \\
B4 & 4 & 0,058 & 187 & 338 & 0,89 & 0,086 & 4 & 0,079 & 0,006 & 0,115 & 60 \\
B5 & 21 & 0,067 & 191 & 238 & 1 & 0,096 & 14 & 0,078 & 0,007 & 0,077 & 48 \\
B6 & 19 & 0,036 & 182 & 201 & 1,06 & 0,022 & 9 & 0,010 & 0,063 & 0,009 & 56 \\
B7 & 11 & 0,046 & 174 & 238 & 1,21 & 0,079 & 1 & 0,059 & 0,026 & 0,059 & 65 \\
B8 & 82 & 0,080 & 226 & 189 & 1,3 & 0,105 & 21 & 0,065 & 0,001 & 0,067 & 53 \\
B9 & 58 & 0,070 & 195 & 173 & 1,32 & 0,102 & 43 & 0,054 & 0,038 & 0,024 & 41 \\
B10 & 2 & 0,005 & 210 & 172 & 1,01 & 0,055 & 1 & 0,042 & 0,016 & 0,042 & 45 \\
B11 & 8 & 0,022 & 193 & 183 & 0,91 & 0,030 & 4 & 0,001 & 0,063 & 0,001 & 65 \\
B12 & 1 & 0,028 & 81 & 135 & 1,06 & 0,057 & 3 & 0,044 & 0,004 & 0,043 & 65 \\
B13 & 33 & 0,066 & 245 & 233 & 1,44 & 0,019 & 31 & 0,016 & 0,068 & 0,014 & 66 \\
B14 & 18 & 0,039 & 153 & 238 & 1,54 & 0,106 & 8 & 0,038 & 0,032 & 0,054 & 47 \\
B15 & 7 & 0,034 & 121 & 309 & 0,81 & 0,092 & 3 & 0,077 & 0,043 & 0,070 & 39 \\
B16 & 1 & 0,056 & 159 & 180 & 1,04 & 0,141 & 6 & 0,050 & 0,013 & 0,051 & 24 \\
B17 & 3 & 0,006 & 197 & 309 & 0,71 & 0,029 & 1 & 0,001 & 0,077 & 0,032 & 77 \\
B18 & 29 & 0,070 & 254 & 239 & 1,97 & 0,050 & 4 & 0,033 & 0,068 & 0,017 & 81 \\
B19 & 25 & 0,048 & 166 & 284 & 0,96 & 0,077 & 24 & 0,049 & 0,028 & 0,049 & 51 \\
B20 & 3 & 0,039 & 214 & 343 & 1,13 & 0,136 & 11 & 0,077 & 0,058 & 0,066 & 67 \\
B21 & 13 & 0,044 & 158 & 220 & 1,29 & 0,086 & 20 & 0,068 & 0,011 & 0,064 & 52 \\
B22 & 14 & 0,015 & 98 & 176 & 1,37 & 0,018 & 9 & 0,005 & 0,057 & 0,006 & 66 \\
B23 & 15 & 0,069 & 325 & 369 & 0,79 & 0,117 & 15 & 0,085 & 0,007 & 0,097 & 59 \\
\hline
\end{tabular}

Adım 2: Normalize Edilmiş Karar Matrisinin Oluşturulması

Tablo 10. Normalize Edilmiş Karar Matrisi

\begin{tabular}{|c|c|c|c|c|c|c|c|c|c|c|c|}
\hline & K1 & K2 & K3 & K4 & K5 & K6 & K7 & K8 & K9 & K10 & K11 \\
\hline B1 & 0,0138 & 0,0531 & 0,0389 & 0,0397 & 0,0343 & 0,0461 & 0,0031 & 0,0591 & 0,0125 & 0,0579 & 0,0438 \\
\hline B2 & 0,0511 & 0,0526 & 0,0387 & 0,0425 & 0,0439 & 0,0723 & 0,2205 & 0,0707 & 0,0053 & 0,0677 & 0,0438 \\
\hline B3 & 0,2141 & 0,0446 & 0,0320 & 0,0305 & 0,0428 & 0,0396 & 0,0559 & 0,0352 & 0,0189 & 0,0396 & 0,0612 \\
\hline B4 & 0,0079 & 0,0543 & 0,0447 & 0,0633 & 0,0343 & 0,0483 & 0,0124 & 0,0707 & 0,0082 & 0,1008 & 0,0453 \\
\hline B5 & 0,0413 & 0,0634 & 0,0456 & 0,0446 & 0,0385 & 0,0536 & 0,0435 & 0,0703 & 0,0100 & 0,0675 & 0,0363 \\
\hline B6 & 0,0373 & 0,0342 & 0,0435 & 0,0376 & 0,0408 & 0,0125 & 0,0280 & 0,0092 & 0,0888 & 0,0077 & 0,0423 \\
\hline B7 & 0,0216 & 0,0433 & 0,0415 & 0,0446 & 0,0466 & 0,0445 & 0,0031 & 0,0532 & 0,0360 & 0,0517 & 0,0491 \\
\hline B8 & 0,1611 & 0,0759 & 0,0540 & 0,0354 & 0,0501 & 0,0586 & 0,0652 & 0,0587 & 0,0011 & 0,0585 & 0,0400 \\
\hline B9 & 0,1139 & 0,0664 & 0,0466 & 0,0324 & 0,0509 & 0,0569 & 0,1335 & 0,0482 & 0,0537 & 0,0211 & 0,0310 \\
\hline B10 & 0,0039 & 0,0048 & 0,0501 & 0,0322 & 0,0389 & 0,0309 & 0,0031 & 0,0375 & 0,0229 & 0,0365 & 0,0340 \\
\hline B11 & 0,0157 & 0,0206 & 0,0461 & 0,0343 & 0,0351 & 0,0169 & 0,0124 & 0,0006 & 0,0888 & 0,0005 & 0,0491 \\
\hline B12 & 0,0020 & 0,0261 & 0,0193 & 0,0253 & 0,0408 & 0,0318 & 0,0093 & 0,0397 & 0,0055 & 0,0376 & 0,0491 \\
\hline B13 & 0,0648 & 0,0626 & 0,0585 & 0,0436 & 0,0555 & 0,0108 & 0,0963 & 0,0140 & 0,0947 & 0,0123 & 0,0498 \\
\hline B14 & 0,0354 & 0,0366 & 0,0365 & 0,0446 & 0,0593 & 0,0591 & 0,0248 & 0,0344 & 0,0447 & 0,0467 & 0,0355 \\
\hline B15 & 0,0138 & 0,0322 & 0,0289 & 0,0579 & 0,0312 & 0,0517 & 0,0093 & 0,0686 & 0,0606 & 0,0608 & 0,0295 \\
\hline B16 & 0,0020 & 0,0527 & 0,0380 & 0,0337 & 0,0401 & 0,0788 & 0,0186 & 0,0451 & 0,0187 & 0,0447 & 0,0181 \\
\hline B17 & 0,0059 & 0,0061 & 0,0470 & 0,0579 & 0,0274 & 0,0163 & 0,0031 & 0,0007 & 0,1085 & 0,0277 & 0,0582 \\
\hline B18 & 0,0570 & 0,0665 & 0,0606 & 0,0448 & 0,0759 & 0,0278 & 0,0124 & 0,0294 & 0,0959 & 0,0153 & 0,0612 \\
\hline B19 & 0,0491 & 0,0458 & 0,0396 & 0,0532 & 0,0370 & 0,0433 & 0,0745 & 0,0437 & 0,0390 & 0,0426 & 0,0385 \\
\hline B20 & 0,0059 & 0,0364 & 0,0511 & 0,0642 & 0,0435 & 0,0759 & 0,0342 & 0,0693 & 0,0808 & 0,0574 & 0,0506 \\
\hline B21 & 0,0255 & 0,0419 & 0,0377 & 0,0412 & 0,0497 & 0,0485 & 0,0621 & 0,0609 & 0,0153 & 0,0561 & 0,0393 \\
\hline B22 & 0,0275 & 0,0144 & 0,0234 & 0,0330 & 0,0528 & 0,0103 & 0,0280 & 0,0049 & 0,0795 & 0,0049 & 0,0498 \\
\hline B23 & 0,0295 & 0,0656 & 0,0776 & 0,0635 & 0,0304 & 0,0653 & 0,0466 & 0,0760 & 0,0105 & 0,0843 & 0,0446 \\
\hline
\end{tabular}

Eşitlik 6 yardımı ile normalize edilmiş değerler elde edilmiş ve bu değerlerden oluşturulan matris Tablo 10'da gösterilmiştir. 
Adım 3: Ağırlıklandırılmış Karar Matrisinin Oluşturulması

Normalize edilmiş değerler ile Entropi yöntemi ile elde edilen her bir kritere ait ağırlık değerlerinin çarpımı ile ağırlıklandırılmış karar matrisi oluşturulmuştur. Kullanılan ağırlık değerleri ise Tablo 8'de verilmiştir. Eşitlik 7 yardımı ile ağırlıklandırılmış karar matrisi elde edilmiş olup değerler Tablo 11'de gösterilmiştir.

Tablo 11. A ̆̆ırlıklandırılmış Karar Matrisi

\begin{tabular}{|c|c|c|c|c|c|c|c|c|c|c|c|}
\hline & K1 & K2 & K3 & K4 & K5 & K6 & K7 & K8 & K9 & K10 & K11 \\
\hline B1 & 0,0005 & 0,0054 & 0,0045 & 0,0047 & 0,0041 & 0,0047 & 0,0001 & 0,0053 & 0,0008 & 0,0052 & 0,0052 \\
\hline B3 & 0,0084 & 0,0046 & 0,0037 & 0,0036 & 0,0051 & 0,0040 & 0,0024 & 0,0032 & 0,0013 & 0,0035 & 0,0072 \\
\hline B5 & 0,0016 & 0,0065 & 0,0053 & 0,0052 & 0,0046 & 0,0054 & 0,0018 & 0,0063 & 0,0007 & 0,0060 & 0,0043 \\
\hline B6 & 0,0015 & 0,0035 & 0,0050 & 0,0044 & 0,0048 & 0,0013 & 0,0012 & 0,0008 & 0,0059 & 0,0007 & 0,0050 \\
\hline B7 & 0,0008 & 0,0044 & 0,0048 & 0,0052 & 0,0055 & 0,0045 & 0,0001 & 0,0048 & 0,0024 & 0,0046 & 0,0058 \\
\hline B10 & 0,0002 & 0,0005 & 0,0058 & 0,0038 & 0,0046 & 0,0031 & 0,0001 & 0,0034 & 0,0015 & 0,0033 & 0,0040 \\
\hline B11 & 0,0006 & 0,0021 & 0,0053 & 0,0040 & 0,0041 & 0,0017 & 0,0005 & 0,0001 & 0,0059 & 0,0000 & 0,0058 \\
\hline B12 & 0,0001 & 0,0027 & 0,0022 & 0,0030 & 0,0048 & 0,0032 & 0,0004 & 0,0036 & 0,0004 & 0,0034 & 0,0058 \\
\hline B13 & 0,0025 & 0,0064 & 0,0068 & 0,0051 & 0,0066 & 0,0011 & 0,0041 & 0,0013 & 0,0063 & 0,0011 & 0,0059 \\
\hline B14 & 0,0014 & 0,0037 & 0,0042 & 0,0052 & 0,0070 & 0,0060 & 0,0010 & 0,0031 & 0,0030 & 0,0042 & 0,0042 \\
\hline B19 & 0,0019 & 0,0047 & 0,0046 & 0,0062 & 0,0044 & 0,0044 & 0,0031 & 0,0039 & 0,0026 & 0,0038 & 0,0046 \\
\hline B20 & 0,0002 & 0,0037 & 0,0059 & 0,0075 & 0,0051 & 0,0077 & 0,0014 & 0,0062 & 0,0054 & 0,0051 & 0,0060 \\
\hline B21 & 0,0010 & 0,0043 & 0,0044 & 0,0048 & 0,0059 & 0,0049 & 0,0026 & 0,0055 & 0,0010 & 0,0050 & 0,0046 \\
\hline B22 & 0,0011 & 0,0015 & 0,0027 & 0,0039 & 0,0062 & 0,0010 & 0,0012 & 0,0004 & 0,0053 & 0,0004 & 0,0059 \\
\hline B23 & 0,0012 & 0,0067 & 0,0090 & 0,0074 & 0,0036 & 0,0066 & 0,0020 & 0,0068 & 0,0007 & 0,0075 & 0,0053 \\
\hline
\end{tabular}

Adım 4-5: Faydalı - Faydasız Ölçütlerin ve $Q_{i}$ Göreceli Önem Değerlerinin Hesaplanmast

İlk olarak Eşitlik 8 ile faydalı ölçütler ve Eşitlik 9 ile de faydasız ölçütler hesaplanmıştır. Daha sonra hesaplanan bu değerler yardımıyla göreceli önem değerleri Eşitlik 10 ile hesaplanmıştır. Elde edilen değerler Tablo 12 'de gösterilmiştir. 
Tablo 12. $S_{i}^{+}, S_{i}^{-}$ve $Q_{i}$ Değerleri

\begin{tabular}{|c|c|c|c|c|c|}
\hline & \multirow[t]{2}{*}{$S_{i}^{+}$} & \multirow[t]{2}{*}{$S_{\tilde{i}}^{-}$} & \multirow{2}{*}{$\frac{1}{S_{i}^{-}}$} & $\sum_{\tilde{i}=1}^{m} S_{\tilde{i}}^{-}$ & \multirow[t]{2}{*}{$Q_{i}$} \\
\hline & & & & $\overline{S_{i}^{-} \cdot \sum_{i=1}^{m} \frac{1}{S_{i}^{-}}}$ & \\
\hline B1 & 0,0161 & 0,0244 & 40,9496 & 0,0296 & 0,0457 \\
\hline B2 & 0,0303 & 0,0263 & 38,0924 & 0,0275 & 0,0579 \\
\hline B3 & 0,0225 & 0,0244 & 41,0060 & 0,0296 & 0,0521 \\
\hline B4 & 0,0176 & 0,0316 & 31,6747 & 0,0229 & 0,0405 \\
\hline B5 & 0,0217 & 0,0261 & 38,3700 & 0,0277 & 0,0494 \\
\hline B6 & 0,0082 & 0,0259 & 38,6289 & 0,0279 & 0,0361 \\
\hline B7 & 0,0147 & 0,0284 & 35,2243 & 0,0255 & 0,0401 \\
\hline B8 & 0,0280 & 0,0264 & 37,9312 & 0,0274 & 0,0554 \\
\hline B9 & 0,0270 & 0,0243 & 41,0872 & 0,0297 & 0,0567 \\
\hline B10 & 0,0073 & 0,0230 & 43,4735 & 0,0314 & 0,0387 \\
\hline B11 & 0,0050 & 0,0253 & 39,5582 & 0,0286 & 0,0336 \\
\hline B12 & 0,0099 & 0,0196 & 51,1142 & 0,0369 & 0,0469 \\
\hline B13 & 0,0154 & 0,0318 & 31,4816 & 0,0228 & 0,0381 \\
\hline B14 & 0,0152 & 0,0278 & 35,9322 & 0,0260 & 0,0412 \\
\hline B15 & 0,0156 & 0,0268 & 37,3365 & 0,0270 & 0,0426 \\
\hline B16 & 0,0183 & 0,0205 & 48,8264 & 0,0353 & 0,0535 \\
\hline B17 & 0,0027 & 0,0321 & 31,1879 & 0,0225 & 0,0252 \\
\hline B18 & 0,0150 & 0,0362 & 27,5911 & 0,0199 & 0,0349 \\
\hline B19 & 0,0180 & 0,0262 & 38,2089 & 0,0276 & 0,0457 \\
\hline B20 & 0,0193 & 0,0351 & 28,4783 & 0,0206 & 0,0399 \\
\hline B21 & 0,0183 & 0,0258 & 38,8135 & 0,0281 & 0,0463 \\
\hline B22 & 0,0052 & 0,0244 & 40,9041 & 0,0296 & 0,0348 \\
\hline B23 & 0,0232 & 0,0336 & 29,8011 & 0,0215 & 0,0448 \\
\hline \multicolumn{2}{|c|}{ TOPLAM } & 0,6257 & 865,6716 & & \\
\hline
\end{tabular}

Adım 6: En Yüksek Göreceli Önem Değerinin Hesaplanması

En yüksek göreceli önem değeri Eşitlik 11 yardımı ile hesaplanmıştır. $Q_{\max }=0,057854$

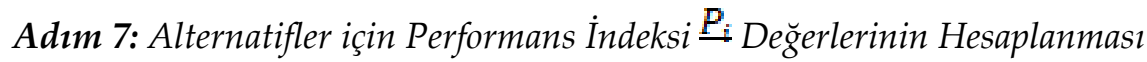

En yüksek göreceli önem değeri yardımı ile her bir alternatif büyükşehre ait performans indeksi değerleri Eşitlik 12 yardımı ile hesaplanmıştır. Elde edilen değerler Tablo 13'de verilmiştir. 
Tablo 13. Performans İndeksi $\left(\mathrm{P}_{\mathrm{i}}\right)$ Değerleri

\begin{tabular}{ll}
\hline $\begin{array}{l}\text { ALTERNATIFLER } \\
\text { (BÜYÜKŞEHİRLER) }\end{array}$ & $\boldsymbol{P}_{\boldsymbol{i}}$ \\
\hline B1 & 78,91125524 \\
B2 & 100 \\
B3 & 90,06230496 \\
B4 & 70,00606535 \\
B5 & 85,3625833 \\
B6 & 62,4774896 \\
B7 & 69,35636994 \\
B8 & 95,80985695 \\
B9 & 97,92650346 \\
B10 & 66,87260213 \\
B11 & 58,08183816 \\
B12 & 80,99026211 \\
B13 & 65,87146427 \\
B14 & 71,21455264 \\
B15 & 73,62711518 \\
B16 & 92,55428378 \\
B17 & 43,62219622 \\
B18 & 60,37797007 \\
B19 & 78,93151228 \\
B20 & 68,89694833 \\
B21 & 80,05338834 \\
B22 & 60,09949708 \\
B23 & 77,39495907 \\
\hline
\end{tabular}

Büyükşehirler aldıkları Performans İndeksi $\mathrm{P}_{\mathrm{i}}$ Değerlerine göre sıralanmaktadır. Tablo 13'ten de görüldüğü üzere aldığı 100 değeri ile en yüksek $P_{1}$ değerini alan büyükşehir B2 kodlu Ankara büyükşehri olmuştur. COPRAS yöntemine göre yapılan çevresel performans değerlendirmesinde Ankara kenti ilk sırada yer almıştır.

\section{ARAS Yöntemi İle Büyükşehirlerin Çevresel Performanslarının Anali- zi}

COPRAS yönteminde olduğu gibi Entropi yöntemi ile kriterlerin ağırlıklarının bulunmasından sonra ARAS yöntemi ile de büyükşehirlerin çevresel performansları değerlendirilmiş ve sıralamaları elde edilmiştir. Değerlendirmede kullanılan alternatifler (büyükşehirler) ve kodları Tab- 
lo 2'de gösterilmiş olup değerlendirmede kullanılan kriterler ve kodlar ise Tablo $3^{\prime}$ de gösterilmiştir.

\section{Adım 1: Karar Matrisinin Oluşturulması}

ARAS yönteminde karar matrisinin oluşturulması COPRAS ve Entropi yöntemlerinden farklıdır. ARAS yönteminde başlangıç karar matrisinde her bir kritere ait optimal değerlerden oluşan bir satır eklenmiştir. Kriterlerin maksimizasyon ya da minimizasyon yönlü olmasına göre optimal değerler belirlenmiş ve karar matrisine eklenmiştir. Oluşturulan karar matrisi Tablo 14'de gösterilmiştir.

Tablo 14. Karar Matrisi

\begin{tabular}{llllllllllll}
\hline & K1 & K2 & K3 & K4 & K5 & K6 & K7 & K8 & K9 & K10 & K11 \\
\hline & max & max & min & min & min & max & max & max & min & min & min \\
\hline Optimum & 109 & 0,080 & 81 & 135 & 0,71 & 0,141 & 71 & 0,085 & 0,001 & 0,001 & 24 \\
B1 & 7 & 0,056 & 163 & 212 & 0,89 & 0,082 & 1 & 0,066 & 0,009 & 0,066 & 58 \\
B2 & 26 & 0,056 & 162 & 227 & 1,14 & 0,129 & 71 & 0,079 & 0,004 & 0,078 & 58 \\
B3 & 109 & 0,047 & 134 & 163 & 1,11 & 0,071 & 18 & 0,039 & 0,014 & 0,045 & 81 \\
B4 & 4 & 0,058 & 187 & 338 & 0,89 & 0,086 & 4 & 0,079 & 0,006 & 0,115 & 60 \\
B5 & 21 & 0,067 & 191 & 238 & 1 & 0,096 & 14 & 0,078 & 0,007 & 0,077 & 48 \\
B6 & 19 & 0,036 & 182 & 201 & 1,06 & 0,022 & 9 & 0,010 & 0,063 & 0,009 & 56 \\
B7 & 11 & 0,046 & 174 & 238 & 1,21 & 0,079 & 1 & 0,059 & 0,026 & 0,059 & 65 \\
B8 & 82 & 0,080 & 226 & 189 & 1,3 & 0,105 & 21 & 0,065 & 0,001 & 0,067 & 53 \\
B9 & 58 & 0,070 & 195 & 173 & 1,32 & 0,102 & 43 & 0,054 & 0,038 & 0,024 & 41 \\
B10 & 2 & 0,005 & 210 & 172 & 1,01 & 0,055 & 1 & 0,042 & 0,016 & 0,042 & 45 \\
B11 & 8 & 0,022 & 193 & 183 & 0,91 & 0,030 & 4 & 0,001 & 0,063 & 0,001 & 65 \\
B12 & 1 & 0,028 & 81 & 135 & 1,06 & 0,057 & 3 & 0,044 & 0,004 & 0,043 & 65 \\
B13 & 33 & 0,066 & 245 & 233 & 1,44 & 0,019 & 31 & 0,016 & 0,068 & 0,014 & 66 \\
B14 & 18 & 0,039 & 153 & 238 & 1,54 & 0,106 & 8 & 0,038 & 0,032 & 0,054 & 47 \\
B15 & 7 & 0,034 & 121 & 309 & 0,81 & 0,092 & 3 & 0,077 & 0,043 & 0,070 & 39 \\
B16 & 1 & 0,056 & 159 & 180 & 1,04 & 0,141 & 6 & 0,050 & 0,013 & 0,051 & 24 \\
B17 & 3 & 0,006 & 197 & 309 & 0,71 & 0,029 & 1 & 0,001 & 0,077 & 0,032 & 77 \\
B18 & 29 & 0,070 & 254 & 239 & 1,97 & 0,050 & 4 & 0,033 & 0,068 & 0,017 & 81 \\
B19 & 25 & 0,048 & 166 & 284 & 0,96 & 0,077 & 24 & 0,049 & 0,028 & 0,049 & 51 \\
B20 & 3 & 0,039 & 214 & 343 & 1,13 & 0,136 & 11 & 0,077 & 0,058 & 0,066 & 67 \\
B21 & 13 & 0,044 & 158 & 220 & 1,29 & 0,086 & 20 & 0,068 & 0,011 & 0,064 & 52 \\
B22 & 14 & 0,015 & 98 & 176 & 1,37 & 0,018 & 9 & 0,005 & 0,057 & 0,006 & 66 \\
B23 & 15 & 0,069 & 325 & 339 & 0,79 & 0,117 & 15 & 0,085 & 0,007 & 0,097 & 59 \\
\hline
\end{tabular}

Adım 2: Karar Matrisinin Normalize Edilmesi

Maksimizasyon yönlü olarak belirlenen kriterlerin normalizasyonu Eşitlik 13 yardımı ile hesaplanmış olup minimizasyon yönlü olarak belirle- 
nen kriterlerin normalizasyonu ise Eşitlik 14 yardımı ile hesaplanmıştır. Elde edilen değerler ise Tablo 15'de gösterilmiştir.

Tablo 15. Normalize Edilmiş Karar Matrisi

\begin{tabular}{|c|c|c|c|c|c|c|c|c|c|c|c|}
\hline & K1 & $\mathrm{K} 2$ & K3 & $\mathrm{K} 4$ & K5 & K6 & K7 & K8 & K9 & K10 & K11 \\
\hline & $\max$ & $\max$ & $\min$ & $\min$ & $\min$ & $\max$ & $\max$ & $\max$ & $\min$ & $\min$ & $\min$ \\
\hline Optimum & 0,176 & 0,071 & 0,082 & 0,066 & 0,061 & 0,073 & 0,181 & 0,071 & 0,302 & 0,410 & 0,089 \\
\hline B1 & 0,011 & 0,049 & 0,041 & 0,042 & 0,049 & 0,043 & 0,003 & 0,055 & 0,027 & 0,004 & 0,037 \\
\hline B2 & 0,042 & 0,049 & 0,041 & 0,039 & 0,038 & 0,067 & 0,181 & 0,066 & 0,064 & 0,003 & 0,037 \\
\hline B3 & 0,176 & 0,041 & 0,050 & 0,054 & 0,039 & 0,037 & 0,046 & 0,033 & 0,018 & 0,005 & 0,026 \\
\hline B4 & 0,006 & 0,050 & 0,036 & 0,026 & 0,049 & 0,045 & 0,010 & 0,066 & 0,041 & 0,002 & 0,035 \\
\hline B5 & 0,034 & 0,059 & 0,035 & 0,037 & 0,044 & 0,050 & 0,036 & 0,065 & 0,034 & 0,003 & 0,044 \\
\hline B6 & 0,031 & 0,032 & 0,037 & 0,044 & 0,041 & 0,012 & 0,023 & 0,009 & 0,004 & 0,027 & 0,038 \\
\hline B7 & 0,018 & 0,040 & 0,038 & 0,037 & 0,036 & 0,041 & 0,003 & 0,049 & 0,009 & 0,004 & 0,033 \\
\hline B8 & 0,133 & 0,071 & 0,029 & 0,047 & 0,034 & 0,054 & 0,053 & 0,055 & 0,302 & 0,004 & 0,040 \\
\hline B9 & 0,094 & 0,062 & 0,034 & 0,051 & 0,033 & 0,053 & 0,109 & 0,045 & 0,006 & 0,010 & 0,052 \\
\hline B10 & 0,003 & 0,005 & 0,032 & 0,051 & 0,043 & 0,029 & 0,003 & 0,035 & 0,015 & 0,006 & 0,047 \\
\hline B11 & 0,013 & 0,019 & 0,034 & 0,048 & 0,048 & 0,016 & 0,010 & 0,001 & 0,004 & 0,410 & 0,033 \\
\hline B12 & 0,002 & 0,024 & 0,082 & 0,066 & 0,041 & 0,030 & 0,008 & 0,037 & 0,062 & 0,006 & 0,033 \\
\hline B13 & 0,053 & 0,058 & 0,027 & 0,038 & 0,030 & 0,010 & 0,079 & 0,013 & 0,004 & 0,017 & 0,032 \\
\hline B14 & 0,029 & 0,034 & 0,043 & 0,037 & 0,028 & 0,055 & 0,020 & 0,032 & 0,008 & 0,004 & 0,045 \\
\hline B15 & 0,011 & 0,030 & 0,055 & 0,029 & 0,054 & 0,048 & 0,008 & 0,064 & 0,006 & 0,003 & 0,055 \\
\hline B16 & 0,002 & 0,049 & 0,042 & 0,049 & 0,042 & 0,073 & 0,015 & 0,042 & 0,018 & 0,005 & 0,089 \\
\hline B17 & 0,005 & 0,006 & 0,034 & 0,029 & 0,061 & 0,015 & 0,003 & 0,001 & 0,003 & 0,007 & 0,028 \\
\hline B18 & 0,047 & 0,062 & 0,026 & 0,037 & 0,022 & 0,026 & 0,010 & 0,027 & 0,004 & 0,014 & 0,026 \\
\hline B19 & 0,040 & 0,043 & 0,040 & 0,031 & 0,045 & 0,040 & 0,061 & 0,041 & 0,009 & 0,005 & 0,042 \\
\hline B20 & 0,005 & 0,034 & 0,031 & 0,026 & 0,039 & 0,070 & 0,028 & 0,064 & 0,004 & 0,004 & 0,032 \\
\hline B21 & 0,021 & 0,039 & 0,042 & 0,040 & 0,034 & 0,045 & 0,051 & 0,057 & 0,022 & 0,004 & 0,041 \\
\hline B22 & 0,023 & 0,013 & 0,068 & 0,050 & 0,032 & 0,010 & 0,023 & 0,005 & 0,004 & 0,042 & 0,032 \\
\hline B23 & 0,024 & 0,061 & 0,020 & 0,026 & 0,055 & 0,061 & 0,038 & 0,071 & 0,032 & 0,002 & 0,036 \\
\hline
\end{tabular}

Adım 3: Ağırlıklandırılmış Matrisin Oluşturulması

Entropi yöntemi ile elde edilen kriter ağırlıkları ile normalize edilmiş değerler çarpılarak ağırlıklandırılmış matris elde edilmiştir. Tablo 8'de Entropi yöntemi ile elde edilen ağırlık değerleri gösterilmiştir. Ağırlıklandırılmış matris değerleri Eşitlik 15 yardımı ile elde edilmiştir ve bu değerlerden oluşan matris Tablo 16' da verilmiştir. 
Tablo 16. Ă̆ırlıklandırılmış Matris

\begin{tabular}{|c|c|c|c|c|c|c|c|c|c|c|c|}
\hline & K1 & K2 & K3 & K4 & K5 & K6 & K7 & K8 & K9 & K10 & K11 \\
\hline & $\max$ & $\max$ & $\min$ & $\min$ & $\min$ & $\max$ & $\max$ & $\max$ & $\min$ & $\min$ & $\min$ \\
\hline Optimum & 0,0069 & 0,0072 & 0,0095 & 0,0077 & 0,0073 & 0,0074 & 0,0076 & 0,0063 & 0,0201 & 0,0366 & 0,0105 \\
\hline B1 & 0,0004 & 0,0050 & 0,0047 & 0,0049 & 0,0058 & 0,0043 & 0,0001 & 0,0049 & 0,0018 & 0,0003 & 0,0043 \\
\hline B2 & 0,0016 & 0,0050 & 0,0048 & 0,0046 & 0,0045 & 0,0068 & 0,0076 & 0,0059 & 0,0043 & 0,0003 & 0,0043 \\
\hline B3 & 0,0069 & 0,0042 & 0,0058 & 0,0064 & 0,0046 & 0,0037 & 0,0019 & 0,0029 & 0,0012 & 0,0005 & 0,0031 \\
\hline B4 & 0,0003 & 0,0052 & 0,0041 & 0,0031 & 0,0058 & 0,0045 & 0,0004 & 0,0059 & 0,0028 & 0,0002 & 0,0042 \\
\hline B7 & 0,0007 & 0,0041 & 0,0044 & 0,0044 & 0,0043 & 0,0042 & 0,0001 & 0,0044 & 0,0006 & 0,0004 & 0,0039 \\
\hline B8 & 0,0052 & 0,0072 & 0,0034 & 0,0055 & 0,0040 & 0,0055 & 0,0023 & 0,0049 & 0,0201 & 0,0003 & 0,0047 \\
\hline B9 & 0,0037 & 0,0063 & 0,0040 & 0,0060 & 0,0039 & 0,0053 & 0,0046 & 0,0040 & 0,0004 & 0,0009 & 0,0061 \\
\hline B10 & 0,0001 & 0,0005 & 0,0037 & 0,0060 & 0,0051 & 0,0029 & 0,0001 & 0,0031 & 0,0010 & 0,0005 & 0,0056 \\
\hline B11 & 0,0005 & 0,0020 & 0,0040 & 0,0057 & 0,0057 & 0,0016 & 0,0004 & 0,0001 & 0,0003 & 0,0366 & 0,0039 \\
\hline B16 & 0,0001 & 0,0050 & 0,0049 & 0,0058 & 0,0050 & 0,0074 & 0,0006 & 0,0038 & 0,0012 & 0,0004 & 0,0105 \\
\hline B17 & 0,0002 & 0,0006 & 0,0039 & 0,0034 & 0,0073 & 0,0015 & 0,0001 & 0,0001 & 0,0002 & 0,0007 & 0,0033 \\
\hline B18 & 0,0018 & 0,0063 & 0,0030 & 0,0043 & 0,0026 & 0,0026 & 0,0004 & 0,0024 & 0,0002 & 0,0012 & 0,0031 \\
\hline B19 & 0,0016 & 0,0043 & 0,0046 & 0,0037 & 0,0054 & 0,0041 & 0,0026 & 0,0036 & 0,0006 & 0,0004 & 0,0049 \\
\hline B20 & 0,0002 & 0,0035 & 0,0036 & 0,0030 & 0,0046 & 0,0071 & 0,0012 & 0,0058 & 0,0003 & 0,0003 & 0,0038 \\
\hline B21 & 0,0008 & 0,0040 & 0,0049 & 0,0047 & 0,0040 & 0,0045 & 0,0021 & 0,0051 & 0,0015 & 0,0003 & 0,0048 \\
\hline B22 & 0,0009 & 0,0014 & 0,0079 & 0,0059 & 0,0038 & 0,0010 & 0,0010 & 0,0004 & 0,0003 & 0,0038 & 0,0038 \\
\hline B23 & 0,024 & 0,061 & 0,020 & 0,026 & 0,055 & 0,061 & 0,038 & 0,071 & 0,032 & 0,002 & 0,036 \\
\hline
\end{tabular}

Adım 4-5: Optimallik Fonksiyon Değgerlerinin $\left(\underline{S}_{\tilde{i}}\right)$ ve Her Bir Alternatife Ait Fayda Derecesinin $\left(\underline{K_{i}}\right)$ Hesaplanmast

Optimallik fonksiyon değerleri $\left(S_{i}\right)$ Eşitlik 16 yardımı ile elde edilmiştir. Elde edilen bu değerler yardımı ile her bir alternatife ait fayda dereceleri $\left({ }{ }_{i}\right)$ hesaplanmıştır. Hesaplama Eşitlik 17 yardımı ile yapılmıştır. Bulunan değerler Tablo 17'de gösterilmiştir.

Tablo 17. $S_{\bar{i}}$ ve $K_{\bar{i}}$ Değerleri

\begin{tabular}{lll}
\hline & $\boldsymbol{S}_{\boldsymbol{i}}$ & $\boldsymbol{K}_{\tilde{i}}$ \\
\hline Optimum & 0,127121401 & 1 \\
B1 & 0,036712246 & 0,288796738 \\
B2 & 0,049650376 & 0,39057449 \\
B3 & 0,041254007 & 0,324524481 \\
B4 & 0,03637845 & 0,286170935 \\
B5 & 0,041061159 & 0,323007446 \\
B6 & 0,028785388 & 0,226440138 \\
B7 & 0,03142269 & 0,247186468 \\
B8 & 0,063073494 & 0,496167392 \\
B9 & 0,045240909 & 0,355887434 \\
B10 & 0,028604865 & 0,225020055 \\
B11 & 0,060603954 & 0,476740763 \\
B12 & 0,039724052 & 0,312489097 \\
B13 & 0,030293994 & 0,238307587
\end{tabular}




\begin{tabular}{lll} 
B14 & 0,032880121 & 0,258651345 \\
B15 & 0,037619285 & 0,295931958 \\
B16 & 0,044524864 & 0,350254666 \\
B17 & 0,021139118 & 0,166290791 \\
B18 & 0,028180568 & 0,22168233 \\
B19 & 0,035828974 & 0,281848486 \\
B20 & 0,03326066 & 0,261644852 \\
B21 & 0,036797171 & 0,289464804 \\
B22 & 0,03001185 & 0,236088097 \\
B23 & 0,039830402 & 0,313325697 \\
\hline
\end{tabular}

ARAS yönteminde büyükşehirler Fayda Derecesine $\left(K_{i}\right)$ göre sıralanmaktadır. En yüksek $\mathrm{K}_{\mathrm{i}}$ değeri B8 kodlu İstanbul büyükşehrine aittir.

\section{COPRAS yöntemi ile ARAS yönteminin Karşılaştırılması}

Entropi yöntemi ile elde edilen ağırlıklar yardımı ile COPRAS ve ARAS yöntemleri uygulanarak 23 büyükşehrin çevresel performansları değerlendirilmiş ve 2 ayrı büyükşehir sıralaması elde edilmiştir. Elde edilen sıralamalar Tablo 18' de verilmiştir.

Tablo 18. COPRAS ve ARAS Yöntemleri İle Elde Edilen Siralamalar

\begin{tabular}{lll|lll}
\hline \multicolumn{2}{c}{ COPRAS } & \multicolumn{3}{c}{ ARAS } \\
\hline SIRA & BÜYÜKŞEHİR & SONUÇ & SIRA & BÜYÜKŞEHİR & SONUÇ \\
\hline $\mathbf{1}$ & Ankara & 100 & $\mathbf{1}$ & İstanbul & 0,496167392 \\
$\mathbf{2}$ & İzmir & 97,92650346 & $\mathbf{2}$ & Hatay & 0,476740763 \\
$\mathbf{3}$ & İstanbul & 95,80985695 & $\mathbf{3}$ & Ankara & 0,39057449 \\
$\mathbf{4}$ & Eskişehir & 92,55428378 & $\mathbf{4}$ & İzmir & 0,355887434 \\
$\mathbf{5}$ & Bursa & 90,06230496 & $\mathbf{5}$ & Eskişehir & 0,350254666 \\
$\mathbf{6}$ & Kocaeli & 85,3625833 & $\mathbf{6}$ & Bursa & 0,324524481 \\
$\mathbf{7}$ & Diyarbakır & 80,99026211 & $\mathbf{7}$ & Kocaeli & 0,323007446 \\
$\mathbf{8}$ & Samsun & 80,05338834 & $\mathbf{8}$ & Trabzon & 0,313325697 \\
$\mathbf{9}$ & Ordu & 78,93151228 & $\mathbf{9}$ & Diyarbakır & 0,312489097 \\
$\mathbf{1 0}$ & Adana & 78,91125524 & $\mathbf{1 0}$ & Erzurum & 0,295931958 \\
$\mathbf{1 1}$ & Trabzon & 77,39495907 & $\mathbf{1 1}$ & Samsun & 0,289464804 \\
$\mathbf{1 2}$ & Erzurum & 73,62711518 & $\mathbf{1 2}$ & Adana & 0,288796738 \\
$\mathbf{1 3}$ & Balıesir & 71,21455264 & $\mathbf{1 3}$ & Gaziantep & 0,286170935 \\
$\mathbf{1 4}$ & Gaziantep & 70,00606535 & $\mathbf{1 4}$ & Ordu & 0,281848486 \\
$\mathbf{1 5}$ & Mersin & 69,35636994 & $\mathbf{1 5}$ & Sakarya & 0,261644852 \\
$\mathbf{1 6}$ & Sakarya & 68,89694833 & $\mathbf{1 6}$ & Balıkesir & 0,258651345 \\
$\mathbf{1 7}$ & Şanlıurfa & 66,87260213 & $\mathbf{1 7}$ & Mersin & 0,247186468 \\
$\mathbf{1 8}$ & Aydın & 65,87146427 & $\mathbf{1 8}$ & Aydın & 0,238307587 \\
$\mathbf{1 9}$ & Konya & 62,4774896 & $\mathbf{1 9}$ & Tekirdağ & 0,236088097 \\
$\mathbf{2 0}$ & Muğla & 60,37797007 & $\mathbf{2 0}$ & Konya & 0,226440138 \\
$\mathbf{2 1}$ & Tekirdă̆ & 60,09949708 & $\mathbf{2 1}$ & Şanlıurfa & 0,225020055 \\
$\mathbf{2 2}$ & Hatay & 58,08183816 & $\mathbf{2 2}$ & Muğla & 0,22168233 \\
$\mathbf{2 3}$ & K.Maraş & 43,62219622 & $\mathbf{2 3}$ & K.Maraş & 0,166290791 \\
\hline
\end{tabular}


Tablo 18'den görüldüğü üzere büyükşehirlerin çevresel performans değerlendirmesinin sonucunda COPRAS yönteminde İstanbul büyükşehri ilk sırada yer alırken ARAS yönteminde ise Ankara büyükşehri ilk sırada yer almıştır. Her iki yöntemde de ilk beşte Ankara, İstanbul, İzmir, Eskişehir büyükşehirleri yer almaktadır. Her iki yöntemde de büyükşehirlerin sıralamaları küçük farklılıklar olmakla birlikte benzerdir. Sıralamanın sonunda ise her iki yöntemde de Kahramanmaraş büyükşehri son sırada yer almıştır.

\section{Sonuç ve Değerlendirme}

Sürdürülebilirlik kavramının kökenleri antik medeniyetlere kadar dayandırılsa da, uluslararası alana taşınması Dünya Çevre ve Kalkınma Komisyonu tarafından 1987 yılında yayımlanan Brundtland Raporu ile gerçekleşmiştir. Bu tarihten sonra yükselişe geçen sürdürülebilirlik olgusu; küresel, ulusal, bölgesel ve yerel olmak üzere birçok farklı ölçekte ele alınmaktadır.

Günümüz dünyasında hızlı nüfus artışına bağlı olarak devasa boyutlara ulaşan tüketim miktarına karşın doğal kaynakların giderek azalması insan neslinin sürdürülebilirliğini tehdit etmektedir. Bu çerçevede, sürdürülebilirliğin çevresel boyutu en az ekonomik ve sosyal boyutu kadar önem arz etmektedir. Dünya uluslarının giriştiği kıyasıya kalkınma yarışının olumsuz dışsallıkları olan çevre kirliliği, ekolojik bozulma, doğal kaynakların tükenmesi ve sera gazı salımının yükselmesi gibi sorunlara sebebiyet vermektedir. Bu sorunlardan en fazla etkilenen mekânlar ise giderek artan nüfusları ile dikkat çeken metropoliten kent alanları olmaktadır. Dünya üzerindeki diğer örnekleri gibi Türkiye'deki büyük ölçekli kentler de çevresel ve ekolojik sorunlar sarmalında bulunmaktadır. Çevresel sorunların aşılmasında performans değerlendirmesi etkin bir rol oynamaktadir.

Bu çalışma ile Türkiye'de bulunan büyükşehirler çevresel performans göstergeleri çerçevesinde değerlendirilmeye çalışılmıştır. Çalışmamızda kullanılan kriterler 11 tanedir. Bu kriterlere ait ağırlıklar Entropi Yöntemi ile hesaplanmış; daha sonra COPRAS ve ARAS yöntemleri aracılığıyla büyükşehirlerin çevresel sıralamaları elde edilmiştir. Yöntemlerin uygulanması sonucunda birbirine benzer siralamalar elde edildiği gözlem- 
lenmiştir. COPRAS yönteminde Ankara, İzmir, İstanbul, Eskişehir ve Bursa kentleri; ARAS yönteminde ise İstanbul, Hatay, Ankara, İzmir ve Eskişehir kentleri çevresel performansı en yüksek olan ilk beş kent olmuşlardır. Her iki yöntemde de Kahramanmaraş kenti çevresel performansı en düşük il olarak dikkat çekmektedir. Diğer kentlere oranla daha yoğun bir nüfusa sahip olan İstanbul, Ankara, İzmir ve Bursa gibi büyükşehirlerin sıralamada üst basamaklarda yer almaları, çevresel farkındalıklarının yüksek olduğu yönünde değerlendirilmiştir. Bu kentlerin üst sıralarda yer almasında daha büyük ölçekli ve küresel nitelikte olmaları, yüksek oranda yerli ve yabancı turist çekmeleri nedeniyle çevresel sorunların çözümüne yönelik daha tecrübeli olmaları, mali kaynaklarının diğer kentlere göre daha yüksek olması gibi faktörlerin payı olduğu düşünülmektedir. Her iki yöntemde de alt sıralarda yer alan Kahramanmaraş, Muğla, Aydın, Konya, Tekirdağ ve Şanlıurfa ise çevresel performansın yükseltilmesi gereken kentler olarak ön plana çıkmaktadır.

Günümüz kentleri çevresel, ekonomik, sosyal ve kültürel birçok alanda rekabet içerisindedir. Bu rekabet New York, Londra, Toronto, Sidney, Tokyo vb. küresel kentlerde daha üst seviyelerde gerçekleşmektedir. Çevresel boyutta sürdürülebilir bir yaşam alanı yaratmak bu rekabette önemli bir yer tutmaktadır. Bu nedenle, sürdürülebilirlik kentlerin önemli gündem maddeleri arasında yer almaktadır. Birçok dünya kenti, ulusal ve uluslararası indeksler aracılığıyla çevresel performanslarını sürekli olarak değerlendirmekte; bu suretle gelişimlerini takip etmektedir.

Başta İstanbul, Ankara, İzmir ve Antalya olmak üzere ülkemiz metropoliten kentleri de bu yarışta ön sıralarda yer almak için çevresel performanslarını değerlendirmek ve geliştirmek zorundadır. Ancak Türkiye'de bu alanda yeterince çalışma yapılmadığı gibi kentlerimiz için mevcut bir sürdürülebilirlik indeksi de bulunmamaktadır.

$\mathrm{Bu}$ çalışma kent yönetimlerine çevresel sıralamadaki yerlerini görebilme fırsatı vermekte; çevresel performans alanında farkındalık yaratmayı hedeflemektedir. Çalışmanın kentler adına karar alma ve uygulama süreçlerinde etkili olacağına inanılmaktadır. Çalışmanın önümüzdeki dönemde ulusal bir kent sürdürülebilirliği indeksi oluşturulması çalışmalarına katkı sağlaması hedeflenmektedir. 


\title{
EXTENDED ABSTRACT
}

\section{Evaluation of Environmental Performances of Metropolitan Cities in Turkey with Entropy Based COPRAS and ARAS Methods}

\author{
Onur Akçakaya - Ezgi Dilan Urmak Akçakaya
}

Ardahan University

Rapid urbanization causes enormous environmental challenges as well as huge social, economic and cultural problems in today's cities. Especially metropolitan cities are human settlements most affected by environmental and ecological threats. On the other hand, the environment is a competition issue for most cities. Cities, turning threats such as environmental pollution and ecological deterioration into an opportunity, are ahead of their other competitors on a global scale. So, the concept of sustainability concerns cities closely today. In the process of creating a sustainable city, measuring environmental performance has great importance.

There are many urban sustainability indexes worldwide. Many cities from Europe, the U.S., China, New Zealand, and Australia prefer the various sustainability indexes that are consistent with their needs and challenges. Nevertheless, Turkish cities are reluctant to measure sustainability compared to other cities in the world. Moreover, there is not a unique environmental urban sustainability index in accordance with the needs of Turkish cities. This situation causes not only the uncertainty of the environmental performance in Turkish cities but also the disadvantage of competition for them.

In this study, it is aimed to evaluate the environmental performance of our metropolitan cities and to raise awareness in this area. More than all it is also purposed to contribute to the creation of an urban sustainability index for Turkish Cities. Such an index provides a comparative, objective and comprehensive assessment of the performances of all cities.

Multi-criteria decision-making methods (COPRAS and ARAS) were used in the evaluation. There are two reasons for preferring COPRAS 
and ARAS methods. First, they give the opportunity to evaluate the criteria that do not have the same units of measurement. Second, the criteria which contradict each other can be evaluated easily by these methods.

Sustainability is a multi-dimensional paradigm and it has social, environmental and economic dimensions. Considering that, a limitation of this paper can be mentioned. In this study, only the environmental dimension of sustainability was evaluated in terms of cities. Therefore, only environmental sustainability criteria were used in the study. In determining the criteria used, the literature review, expert opinions and accessibility of data were effective. Eleven criteria used in the evaluation are; number of wastewater treatment plants, amount of wastewater treated in wastewater treatment plants per person (thousand M3 / year), daily wastewater discharged in municipalities (Liters/Person-Day), daily amount of water taken per person (Liters / Person-Day), average amount of municipal waste per person ( $\mathrm{kg} /$ person-day), capacity of drinking and potable water treatment plant (thousand M3 per year), number of drinking water treatment plants, amount of drinking and potable water treated in treatment plants per person (thousand M3 / year), amount of groundwater taken for drinking and potable water network per capita (thousand M3 / year), amount of surface water taken for drinking and utility water network per capita (thousand M3 / year) ) and particulate matter. When the criterion weights were examined, it was seen that the "K11" coded "particulate matter" criterion has the highest value with the value of "0,1183". For this reason, "K11" was the most important criterion. On the other hand, "the number of wastewater treatment plants" with code "K1" was the least important criterion for environmental performance evaluation with the value of "0.0392".

In the evaluation process, at first, the weights of the criteria were calculated by the Entropy Method. After then the environmental rankings of the metropolitan cities were obtained by COPRAS and ARAS Methods. So, two rankings were obtained as a result of the evaluation of COPRAS and ARAS. In both methods, close sequences were obtained. Istanbul, Ankara, Izmir, Eskisehir, and Bursa were among the best performing cities; Aydın, Konya, Tekirdağ, Muğla, and Kahramanmaraş 
were the least performing cities. So it can be stated that the study revealed the environmental performance of the cities.

In conclusion, it can be stated that the evaluation of environmental sustainability performance is a critical issue for all cities around the world. However, a specific environmental index is as important as the evaluation process for urban areas. So, an indicator tool developed for Turkish Cities has great importance in terms of many aspects. At first, an accessible index easies the evaluation process for all cities. Secondly, it contributes to raising the level of awareness about urban sustainability. Also, urban sustainability performance can be evaluated in a comparative, objective, and inclusive manner. Thus, the cities will be able to measure their own environmental performance and to see their rankings. This situation may increase the competitiveness of the cities as well as speed up the policy transfer process.

\section{Kaynakça / References}

Akçakaya, O. (2016). Kentsel sürdürülebilirliğin uygulanması ve ölçülmesi bağlamında yerel yönetimlerin fonksiyonu. Ardahan Üniversitesi İktisadi ve İdari Bilimler Fakültesi Dergisi, 4, 47-64.

Akçakaya, O. (2017). Yerel sürdürülebilirliğin sağlanmasında etkin bir yaklaşım: Kamu sektörü ve özel sektör ortaklığı. Sakarya İktisat Dergisi, 6(3) ,46-62.

Akten, M. ve Akten, S. (2010). A model approach: An agricultural sector case study for sustainable land use planning. BIBAD, 2, 83-90.

Anders, R. (1991). The sustainable cities movement. Working paper no. 2, Institute for Resources and Security Studies, Cambridge, MA, USA.

Aytaç, A. E. ve Tuş, I. A. (2016). Air Conditioner selection problem with COPRAS and ARAS methods. Manas Journal of Social Studies, 5(2), 124-138.

Bağcl, H. ve Caba, N. (2018). Entropi ve COPRAS yöntemleri kullanılarak menkul kıymet yatırım ortaklıklarının nakit düzeylerinin k1yaslanması. Insan ve Toplum Bilimleri Araştırmaları Dergisi, 7(5), 64-83. 
Beatley, T. (1995). Planning and sustainability: The elements of a new (improved? paradigma. Journal ofplanning Literature, 9( 4), 383395.

Bircan, H., Arslan, R. ve Eleroğlu, H.(2018). MOORA ve COPRAS yöntemleriyle kayseri ilinde kurulabilecek biyogaz tesislerinin optimallik siralaması. International Congress on Politic, Economic and Social Studies, 26-29 October, 2018 Niğde / Turkey

Briassoulis, H. (2001). Sustainable development and its indicators: Through a planner's glass darkly. Journal of Environmental Planning and Management, 44(3), 409-427.

Chatterjee, P., Athawale, V. M. ve Chakraborty, S. (2011). Materials selection using complex proportional assessment and evaluation of mixed data methods. Materials $\mathcal{E}$ Design, 32(2), 851-860.

Couch. C., Karecha, J., Nuissl, H. ve Rink, D. (2005). Decline and sprawl: An evolving type of urban development - Observed in Liverpool and Leipzig. European Planning Studies 13(1), 117-136.

Çakır, E. ve Kutlu Karabıyık, B. (2017). Bütünleşik SWARA-COPRAS yöntemi kullanarak bulut depolama hizmet sağlayıcılarının değerlendirilmesi. Bilişim Teknolojileri Dergisi, 10(4), 417-434.

Diver, G., Newman, P. ve Kenworthy, J. (1996). An evaluation of better cities: Environmental component. Department of Environment, Sport and Territories, Canberra.

Ercan, E. ve Kundakc1, N. (2017). Bir tekstil işletmesi için desen programı seçiminde ARAS ve OCRA yöntemlerinin karşılaştırılması. Afyon Kocatepe Üniversitesi Sosyal Bilimler Dergisi, 19(1), 83-105.

Gök, M. ve Yiğit, S. (2017). Türkiye'deki Büyükşehirlerin sürdürülebilirlik kriterleri açısından incelenmesi yönetim bilimleri dergisi,Journal of Administrative Sciences, 15(30), 253-273.

Kenger, M. D. ve Organ, A. (2017). Banka personel seçiminin çok kriterli karar verme yöntemlerinden entropi temelli aras yöntemi ile değerlendirilmesi. Adnan Menderes Üniversitesi Sosyal Bilimler Enstitüsü Dergisi, 4(4), 152-170.

Kidd, C.V. (1992). The evolution of sustainability. Journal of Agricultural Environmental Ethics, 5(1), 1-26. 
Kutut, V., Zavadskas, E. K. ve Lazauskas, M. (2014), Assessment of priority alternatives for preservationof historic buildings using model based on ARAS and AHP methods. Archives Of Civil And Mechanical Engineering, 14(2), 287-294.

Ma, Y.C., Wang, X.Y. ve Liu, H. (2014). Study on evaluation dimension of sustainable innovative city within the constraints of resources and environment. Proceedings Of International Symposium Management, Innovation and Development.

Maclaren, V. W. (1993). Sustainable urban development in canada: From concept to practice. Toronto: ICURR Press.

Maclaren, V. W. (1996). Urban sustainability reporting. Journal of the American Planning Association, 62(2), 184-202.

Medineckiene, M., Zavadskas, E. K., Bjork, F. ve Turskis, Z. (2015). MultiCriteria Decision-Making system for sustainable building assessment/certification. Archives of Civil and Mechanical Engineering, 15(1),11-18.

Mega, V. ve Pedersen, J. (1998), Urban sustainability indicators, Dublin: European Foundation.

Mitlin, D. ve Satterthwaite, D. (1994). Cities and sustainable development. discussion paper for un global forum, Manchester, IIED, London.

Mulliner, E., Smallbone, K. ve Maliene, V. (2013). An assessment of sustainable housing affordability using a multiple criteria decision making method. Omega, 41(2), 270-279.

Newman, P. W.G. (1999). Sustainability and cities: Extending the metabolism model. Landscape and Urban Planning,44, 219-226.

Newman, P. ve Kenworthy, J. (1999). Sustainability and cities: Overcoming automobile dependence. Island Press, Washington, DC.

Our Common Future (1987). WCED (World Commission on Environment and Development). Oxford: Oxford University Press.

Ömürbek, N. ve Urmak A. E. D. (2018). Forbes 2ooo listesinde yeralan havacılık sektöründeki şirketlerin Entropi, MAUT, COPRAS Ve SAW yöntemleri ile analizi. Süleyman Demirel Üniversitesi İktisadi ve İdari Bilimler Fakültesi Dergisi, 23(1), 257-278. 
Ömürbek, N. ve Eren, H. (2016). PROMETHEE, MOORA VE COPRAS yöntemleri ile oran analizi sonuçlarının değerlendirilmesi: Bir Uygulama. Mehmet Akif Ersoy Üniversitesi Sosyal Bilimler Enstitüsü Dergisi, 8(16), 174-187.

Podvezko, V. (2011). The Comparative analysis of MCDA methods SAW and COPRAS. Inzinerine Ekonomika Engineering Economics, 22(2), 134-146.

Roseland, M. (1992). Toward sustainable Communities. Ottawa, Ontario: National Roundtable on the Environmental and the Economy.

Sarı, E. B. (2017). Endüstri işletmelerinde Ar-Ge projelerini öncelik sıralamasında entropi ağırlıklı topsis yöntemine dayalı çok kriterli bir analiz. International Journal of Academic Value Studies 3(11), 159 $-170$.

Shannon, C. E. (1948). A mathematical theory of communication. Bell System Technical Journal, 27, 379-423.

Shariati, S., Yazdani-Chamzini, A., Salsani, A. ve Tamošaıtıenė, J. (2014). Proposing a new model for waste dump site selection: case study of ayerma phosphate mine. Engineering Economics, 25(4), 410-419.

Sliogeriene, J., Turskis, Z. ve Streimikiene, D. (2013). Analysis and choice of energy generation technologies: the multiple criteria assessment on the case study of lithuania. Energy Procedia, 32, 11-20.

Ulutaş, A. (2018). Entropi temelli ROV yöntemi ile esnek üretim sistemi seçimi. Business and Economics Research Journal, 9(1), 187-194.

Verbruggen, H. ve Kuik, O. (1991). Indicators of sustainable development: an overview. In O. Kuik and H. Verbruggen (Ed.), In search of indicators of sustainable development.

Wang, T.C. ve Lee H. D. (2009). Developing a fuzzy TOPSIS approach based on subjective weights and objective weights. Expert Sysytems With Applications, 36, 8980-8985.

Wong, N. ve Yu, C. (2005). Study of green areas and urban heat island in a tropical city. Habitat International, 29(3), 547-558.

Wu J., Sun J., Liang L. ve Zha Y. (2011). Determination of weights for ultimate cross efficiency using Shannon entropy. Expert System with Application, 38, 5162-5165.

Yıldırım, B. F. (2015). Çok kriterli karar verme problemlerinde ARAS yöntemi. KAய̈ İ̈BF Dergisi, 6(9), 285-296. 
Zavadskas, E. K., Kaklauskas A., Turskıs, Z. Ve Tamošaitiene J. (2009). Multi-Attribute Decision-Making Model by applying grey numbers. Informatica, 20(2), 305-320.

Zavadskas, E. K. ve Turskis, Z. (2010). A new additive ratio assessment (ARAS) method in multicriteria decision-making. Technological and Economic Development of Economy, 16(2), 159-172.

Zavadskas, E. K., Turskis, Z. ve Vilutiene, T. (2010). Multiple criteria analysis of foundation instalment alternatives by applying additive ratio assessment (ARAS) method. Archives Of Civil And Mechanical Engineering, 10(3), 123-141.

Tunca, M.Z., Ömürbek, N., Urmak A. E.D. ve Akçakaya, O. (2018). En değerli 10 küresel markanın çok kriterli karar verme yöntemleri ile değerlendirilmesi. 17. Uluslararası Katılımlı İşletmecilik Kongresi, 1837-1847.

\section{Kaynakça Bilgisi / Citation Information}

Akçakaya, O ve Urmak-Akçakaya, E. D. (2019). Türkiye'deki büyükşehirlerin çevresel performanslarının entropi temelli COPRAS ve ARAS yöntemleri ile değerlendirilmesi. OPUSUluslararası Toplum Araştırmaları Dergisi, 11(18), 1437-1473. DOI: 10.26466/opus. 556278 